Heriberta Castaños y Eduardo Muñiz (coordinadores)

\title{
MITOS Y REALIDADES DE LA CIENCIA EN MÉXICO
}


Mucho se dice sobre ef desanollo y of quehacer cientinco nacional al respecto se han enunciado una intinidad de criticas, asi como de halagos Son tantas y variadas las opiniones que se tienen que resulta difikil distinguir entse lo verdadero y lo talsa. Migas y realidades de lo ciencia en Miexico es un estuerno por brindar mayor contraste ante las distintas posturas de la cliceusion.

Mediante informacion estadistica, peto tambiein recuperando th opinion y experiencia de decenas de cientincos y de quienes toman las decisiones fundamentales en el ambito de las cienciax involucrados diariamente en la investigaxion. el laro otorga al lector una panordmica amena y suficiente para dincernir por si mismo entre los mitos y las werdades de la ciencia en Mexika. 
MITOS Y REALIDADES

DE LA CIENCIA EN MÉXICO 


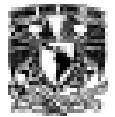

UNIVERSIDAD NACIONAL AUTÓNOMA DE MÉXICO

Dr. José Narro Robles

Rector

Dr. Eduardo Bárzana García

Secretario General

Ing. Leopoldo Silva Gutiérrez

Secretario Administrativo

Dra. Estela Morales Campos

Coordinadora de Humanidades

INSTITUTO DE INVESTIGACIONES ECONÓMICAS

Dra. Verónica Villarespe Reyes

Directora

Mtra. Berenice P. Rodríguez López

Secretaria Académica

Aristeo Tovías García

Secretario Técnico

Marisol Simón Pinero

Jefa del Departamento de Ediciones 


\title{
MITOS Y REALIDADES DE LA CIENCIA EN MÉXICO
}

\author{
Heriberta Castaños \\ Eduardo Muñiz \\ (coordinadores)
}
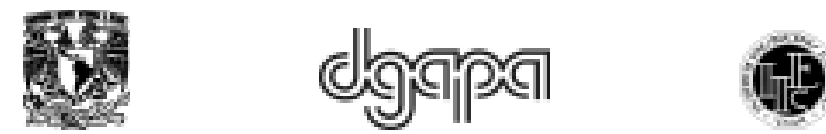

UNIVERSIDAD NACIONAL AUTÓNOMA DE MÉXICO DIRECCIÓN GENERAL ASUNTOS DEL PERSONAL ACADÉMICO INSTITUTO DE INVESTIGACIONES ECONÓMICAS 
Esta investigación, arbitrada por pares académicos, se privilegia con el aval de la institución editora.

Mitos y realidades de la ciencia en México / coordinadores Heriberto Castaños y Eduardo Muñiz. - Primera edición. - México, D.F.: Universidad Nacional Autónoma de México, Instituto de Investigaciones Económicas, 2014. 133 páginas: ilustraciones; $21 \mathrm{~cm}$.

Incluye bibliografías

ISBN 978-607-02-5820-6

1. Ciencia - México. 2. Ciencia y estado-México. 3. Investigación-México. 4. Política cultural - México. I. Castaños, Heriberto. II. Muñiz, Eduardo. I. Universidad Nacional Autónoma de México. Instituto de Investigaciones Económicas.

Primera edición, 7 de octubre de 2014

D.R. C U Universidad Nacional Autónoma de México

Ciudad Universitaria, Coyoacán, 04510, México, D.F.

Instituto DE INVESTIGACIONES ECONÓMICAS

Circuito Mario de la Cueva s/n

Ciudad de la Investigación en Humanidades

04510, México, D.F.

ISBN: 978-607-02-5820-6

Diseño de portada e interiores: Irma Martínez Hidalgo y Marisol Simón. Corrección y cuidado de la edición: Hélida De Sales Y.

Prohibida la reproducción total o parcial por cualquier medio sin la autorización escrita del titular de los derechos patrimoniales.

Impreso y hecho en México 


\section{AGRADECIMIENTOS}

Agradecemos a la Dirección General de Asuntos del Personal Académico (DGAPA) de la UNAM, por apoyarnos en la realización de este Proyecto de Investigación e Innovación Tecnológica (PAPIIT): IN302410 "Mitos y realidades de la ciencia: análisis y estrategias".

Valoramos ampliamente la participación de los investigadores, empresarios y funcionarios que amablemente aceptaron ser entrevistados, así como el trabajo de los prestadores de servicio social proporcionados por la Dirección General de Orientación y Servicios Educativos de la UnAM y de los becarios patrocinados por la DGAPA.

Reconocemos el gran interés que manifestó el doctor Cinna Lomnitz en esta investigación.

Y en particular agradecemos la colaboración de Luz Aida Lozano y de Yolanda Ham Zarco, sin cuya brillante participación no hubiera podido realizarse este proyecto.

Asimismo, a los becarios y prestadores de servicio social que colaboraron en algún punto de la investigación: Adrián Jiménez Martínez, José Antonio Correa Martínez, Viridiana Flores Ochoa, Saraí Maribel Flores Rodríguez, Giovanna Flores Rubio, Emmanuel García Lima, Rocío del Carmen González Ramírez, Dante Luis Granados Vargas, Eduardo Gutiérrez Rojo, Karen Martínez Orta, César Martínez Rodríguez, Sharon Iliana Nieto González, Daniel Olguín Martínez, Carlo Daniel Pineda Almanza, Gustavo Pineda Loperena, Luis David Rodríguez Padilla, Carol Guadalupe Reyes Mata, Arturo David Ríos Alejo, Rebeca Silva Flores. 


\section{ÍNDICE}

InICIOS Y EVOLUCIÓN DE LA CIENCIA EN MÉXICO

Heriberta Castaños Rodríguez

ACTORES DE LA CIENCIA

Yolanda Ham Zarco

Carlo Daniel Pineda

El Estado EN EL DESARROLlo CIENTÍFICO DEL SIGLO XX Erandi González Alamilla

INICIATIVA PRIVADA E INVESTIGACIÓN CIENTÍFICA

Sharon Iliana Nieto González

Emmanuel García Lima

ANÁLISIS DE LAS ENTREVISTAS

EVALUACIÓN Y FINANCIAMIENTO

Heriberta Castaños Rodríguez

INNOVACIÓN

Viridiana Flores Ochoa 
VINCULACIÓN Y COLABORACIÓN

Eduardo Muñiz Trejo $\quad 91$

DiFUSIÓN Y DIVULGACIÓN

Eduardo Muñiz Trejo 107

$\begin{array}{lr}\text { CONCLUSIONES } & 118\end{array}$

$\begin{array}{ll}\text { AnEXo estadístico } & 121\end{array}$ 


\section{INTRODUCCIÓN}

La meta es consolidar un Sistema Nacional de Ciencia y Tecnología que responda a las demandas prioritarias del país, que dé solución a problemas y necesidades específicos, y que contribuya a elevar el nivel de vida y el bienestar de la población; para ello se requiere: contar con una política de Estado en la materia; incrementar la capacidad científica y tecnológica del país; y elevar la calidad, la competitividad y la innovación de las empresas.*

La política científica y tecnológica de México ha basado su discurso y su arraigo social en una profunda identificación con el desarrollo de la nación. En efecto, a partir de la creación del Consejo Nacional de Ciencia y Tecnología (Conacyt) en 1971 y, primordialmente, del Sistema Nacional de Investigadores (SNI) en 1984, México ha seguido una filosofía propia en la materia. Se trata de un discurso original sobre la función de la ciencia en la planeación, el desarrollo tecnológico y la innovación.

En este discurso se usa frecuentemente el término sistema para describir las funciones del Conacyt. Pueden citarse, entre otros: el Sistema de Centros Públicos de Investigación Conacyt; el Sistema Integrado de Información sobre Investigación Científica, Desarrollo Tecnológico e Innovación (SIICYT); el Sistema Nacional de Evaluación Científico y Tecnológica

* De la página oficial en internet del Consejo Nacional de Ciencia y Tecnología: www.conacyt.mx/index.php/el-conacyt 
(SNECYT); los Sistemas de Investigación Regionales; los sistemas de información existentes en centros públicos de investigación y otras dependencias, entidades e instituciones de la administración pública federal; los sistemas de información generados por gobiernos estatales y municipales, cámaras industriales y otros agentes del sector privado que voluntariamente decidan incorporarse al SIICYT; y los sistemas de información de las universidades, instituciones de educación superior, centros de investigación y gobiernos de las entidades federativas y de los municipios que hayan establecido convenios con el Conacyt para la integración y actualización del SIICYT; y el empleo frecuente del término sistema en el lenguaje oficial.

Ahora bien, cabe preguntarse: qué es un sistema. En la moderna teoría de los sistemas, éste puede ser cualquier agrupación de actores sociales que comparten actividades e interactúan sobre una base regular. Según Béla $\mathrm{H}$. Bánáthy hay un punto de vista sistémico compartido por muchas disciplinas que se desarrolló inicialmente en la obra de Max Weber y Emilio Durkheim, y evolucionó en la sociología antirreduccionista de Niklas Luhmann, para quien las sociedades son redes de comunicación cada vez más complejas.

Dice Luhmann que el sociólogo es un observador que piensa en tres dimensiones: el tiempo, los objetos y la sociedad. La adquisición de información se efectúa por medio de distinciones: así, el mundo es observado en el tiempo mediante la distinción antes/después, en los objetos con la distinción de las formas, y en lo social vía la distinción yo/el otro. No se trata, aclara Luhmann, de distinguir entre individuos que se relacionan, sino de entender el proceso de las comunicaciones donde el individuo desempeña siempre ambos papeles a la vez: "yo" y "el otro".

Así, la sociología alemana (con pensadores como Habermas, Luhmann y otros) afirma que lo esencial para entender el mundo es la comunicación; gracias a la cual, la sociedad 
reduce su complejidad y se hace manejable por medio de la ciencia, la tecnología y la innovación. Es por eso que la sociedad necesita comunicarse con el científico y viceversa: el científico con la sociedad mediante los subsistemas tales como la política y la economía. En este contexto, es la comunidad científica mexicana la primera en reconocer que la ciencia tiene que evolucionar para beneficio de la sociedad y la humanidad.

La evolución de la ciencia del país puede verse como un acto trascendental de comunicación entre la comunidad científica y la sociedad nacional. Al reconocer su arraigo en la sociedad, la ciencia mexicana asume su destino.

$$
* * * * *
$$

Este libro es resultado del proyecto: IN302410 "Mitos y realidades de la ciencia: análisis y estrategias", del Programa de Apoyo a Proyectos de Investigación e Innovación Tecnológica (PAPIIT) de la Dirección General de Asuntos de Personal Académico (DGAPA) de la Universidad Nacional Autónoma de México (UNAM). Y tiene por objetivo principal proveer de una visión general y sucinta del estado de la investigación científica y humanística en el país, según las opiniones y perspectivas de sus propios actores.

Para ello se entrevistó con detalle a 50 científicos, así como a funcionarios y empresarios de alto nivel. Los investigadores entrevistados provienen de diversas instituciones nacionales, entre ellas la UNAM y sus dependencias foráneas; el Instituto Politécnico Nacional (IPN) y el Centro de Investigación y Estudios Avanzados (Cinvestav); la Universidad Autónoma Metropolitana (UAM) con sus unidades de Azcapotzalco, Iztapalapa, Cuajimalpa y Xochimilco; el Hospital General de México "Dr. Eduardo Liceaga" (HGM) de la Secretaría de Salud del gobierno federal; el Foro Consultivo Científico y Tecnológico; Conacyt; la Academia Mexicana de Ciencias (AMC); la 
Comisión Intersecretarial de Bioseguridad de los Organismos Genéticamente Modificados (Cibiogem), entre otras.

Los resultados son muy interesantes debido a la franqueza y a la gran variedad de personalidades entrevistadas que contribuyeron a este ejercicio. Por razones obvias se preservó el anonimato de todos los involucrados, cuya participación entusiasta merece un cumplido agradecimiento.

El contenido del libro se estructura en tres partes. En la primera se presenta un panorama general de la historia de la ciencia en México. Este apartado es necesario debido a las peculiaridades del país como colonia relativamente aislada del Imperio español, y por los conflictos políticos y bélicos posteriores a la Independencia. Aquí se pretende dar al lector poco familiarizado una perspectiva histórica suficiente para abordar el resto del libro.

En la segunda parte se presentan los participantes de la ciencia mexicana: la iniciativa privada, el Estado y la universidad. Se analizan las circunstancias bajo las cuales se desarrolló tardíamente la comunidad científica en México durante el siglo xx, los principales factores que influyeron en su desarrollo y la forma en cómo los diversos actores se relacionan con la investigación científica y humanística.

En la última parte, se recuperan las opiniones de los entrevistados. Para ello se analizaron cualitativa y cuantitativamente sus respuestas mediante el software N-VIVO ${ }^{\circledR}$ y se compararon entre sí. A partir de ello se identificaron variables que la mayoría de los entrevistados coincidieron en percibir como problemáticas. Para facilitar la lectura, estas variables fueron agrupadas en cuatro categorías:

- Evaluación y financiamiento. Se refiere al control que realizan las instituciones sobre el trabajo de los científicos según su especialidad, con el objetivo de calificar su desempeño y la manera en que son asignados los recursos económicos destinados a la investigación científica. 
- Innovación. Involucra la generación de nuevas ideas, productos, procedimientos o tecnologías.

- Vinculación y colaboración. Se refiere a la relación entre las instituciones públicas y privadas, incluyendo a las universidades. La vinculación se manifiesta de diversas formas, como pueden ser el intercambio de estudiantes entre universidades, la presencia de investigadores en empresas nacionales y extranjeras con la intención de ampliar sus conocimientos, así como la formación de equipos multidisciplinarios entre otros.

- Difusión y divulgación. Incluye la actividad del científico destinada a dar a conocer los resultados de su investigación entre sus pares y difundirlo al público no especializado.

De esta forma se recuperaron respuestas muy interesantes y se obtuvo una "fotografía" de la realidad de la ciencia vista desde sus actores. 


\section{INICIOS Y EVOLUCIÓN \\ DE LA CIENCIA EN MÉXICO}

\section{Heriberta Castaños Rodríguez*}

A lo largo de la historia la búsqueda del conocimiento ha demostrado ser de vital importancia para todos los pueblos y todas las civilizaciones. Por medio del entendimiento y dominación de su entorno, podía garantizarse la sobrevivencia de las sociedades como colectividades humanas. De esta manera, los pueblos siempre han utilizado los conocimientos y estudios alcanzados por las comunidades que les precedieron, ya sea para suscribirlos, complementarlos o refutarlos. Gracias a ello es que el conocimiento tiene una visible continuidad en la historia, así como un carácter acumulativo.

En general, la ciencia es una actividad humana que organiza y construye el conocimiento en términos de explicaciones comprobables y predicciones verificables. En el caso mexicano, la ciencia también es una amalgama de conocimientos provenientes, por un lado, de las comunidades indígenas precoloniales con su propia cosmovisión y con importantes avances en matemáticas, medicina, astronomía y ciencias naturales; y, por otro lado, de la tradición occidental con profundas raíces en las culturas grecolatinas. Esta suma de conocimientos ha estado condicionada por los vaivenes provocados por las

* Investigadora titular, Instituto de Investigaciones Económicas, Universidad Nacional Autónoma de México. Coordinadora del Proyecto PAPIIT IN302410. 
distintas crisis políticas, religiosas, económicas y sociales que ha atravesado el país.

Por ese motivo, tratar de explicar a cabalidad el devenir histórico de la ciencia en México es una tarea muy amplia y compleja que rebasa los objetivos y alcances de este libro. En las líneas siguientes se intentará sintetizar un recuento de los últimos siglos de historia que sirva al lector como contexto mínimo desde el cual abordar los resultados de la presente investigación.

\section{LA PRECARIEDAD DE LA CIENCIA EN LA COLONIA}

Durante los tres siglos que México fue colonia española (del siglo XVI al XVIII), las diversas corrientes científicas que predominaban en Europa llegaron a cuentagotas a la Nueva España y siempre mediante el filtro eclesiástico. En un principio, los primeros novohispanos asimilaron y aprovecharon en alguna medida el saber de los pueblos indígenas referente a la zoología, la botánica, la astronomía, la geografía y la medicina, pero también buena parte de ese conocimiento se perdió o se ignoró debido a que desde la metrópoli, que aún trataba de afianzar la "reconquista española", se ordenó excluir y perseguir conceptos y esquemas de pensamiento que atentasen contra el objetivo de consolidar las ideas de la Corona. De hecho, no sólo se persiguió el conocimiento local, sino que también se rechazaron las nuevas ideas provenientes de la Reforma y del Renacimiento.

Mediante la Inquisición se intentó con cierto éxito imponer en México, por medio de la educación y la fuerza, la cosmovisión vigente en la España de esa época. Debido al temor de poner en tela de juicio las "verdades" divinas aceptadas como ciertas, el desarrollo de las ciencias de alta precisión fue limitado; sólo se toleró la investigación en el área de la minería porque convenía tanto a los criollos como a los españoles, 
quienes percibían el quinto del total de la extracción. El predominio de la superstición y la censura fueron un obstáculo para que el saber científico se desarrollara y difundiera plenamente en todos los niveles [Trabulse, 2003: 65].

En cambio, las humanidades, que no representaban peligro, alcanzaron un gran desarrollo que es conocido como el Siglo de Oro español [Pérez, 2010: 322]. De esa forma, los avances científicos y tecnológicos alcanzados durante los primeros siglos del virreinato fueron modestos comparados con los de otras naciones.

En 1767 fue fundado el Real Colegio de San Ignacio de Loyola, conocido como Colegio de las Vizcaínas, que si bien incluía en sus planes de estudio la educación religiosa, fue la primera institución educativa que no se encontró totalmente bajo tutela eclesiástica. A la creación del Colegio le siguieron otras instituciones de inspiración jesuita como la Real Escuela de Cirugía (1770), la Academia de Artes de San Carlos (1781), el Jardín Botánico de México (1788), el Real Seminario de Minería (1792) y otras instituciones laicas. Aunque finalmente los jesuitas fueron expulsados de México en 1773 por orden del Papa Clemente XIV.

En el Real Seminario de Minería se tradujeron, editaron y publicaron los libros científicos más avanzados de la época, como lo fueron el Tratado de Química de Lavoisier, las Tablas Mineralógicas de Karsten; el Tratado de Amalgamación de Sonneschmidt; los Elementos de Orictognosia de Andrés Manuel del Río; entre otros [Izquierdo, 1958: 271]. Una característica interesante de esta y otras instituciones que se fundaron con fines similares durante el último siglo colonial fue que dependían económicamente de particulares, en este caso de los empresarios mineros. La ausencia de un compromiso claro y coherente de las autoridades con el desarrollo del conocimiento, así como sus miras inmediatistas y destinadas a solucionar problemas muy concretos, serían aspectos a los que tendrían que hacer frente -una vez independizados- los 
países latinoamericanos con el fin de forjar una ciencia nacional:

No se obtuvo la creación de una capacidad científica propiamente dicha en las regiones periféricas, sino únicamente la difusión de la ciencia para ser utilizada con fines prácticos y, además, siempre acotada a ciertas disciplinas o algunos aspectos de ellas. Esta característica de la institucionalización de la ciencia racional se encuentra en el origen de la orientación pragmática, el carácter privado y el consecuente atraso científico que heredaron las colonias al producirse su independencia política [Izquierdo, 1958: 19].

Posteriormente, la crisis que significó la lucha de Independencia a principios del siglo XIX y los conflictos políticos y vicisitudes económicas que tuvo que enfrentar la incipiente nación mexicana en sus primeras décadas de vida independiente, frenaron temporalmente el ritmo de la labor científica en el país ya que no sólo se colapsó la dinámica social, también se vulneraron los vínculos existentes con la élite científica europea, que en ese momento realizaba grandes avances y descubrimientos científicos, como lo son los trabajos de personajes históricos como Darwin, Pasteur, Dalton y Gauss.

El Real Seminario de Minería se quedó prácticamente sin recursos económicos; el número de alumnos se redujo dramáticamente; los cursos eran impartidos de manera irregular, y su nivel era bastante deficiente. Las más importantes instituciones científicas, como el Colegio de Minas y el Jardín Botánico, se encontraban en un estado lamentable. El Colegio de Minas contaba con pocos instrumentos y poco cuidado de los mismos. El Jardín Botánico era sólo un recuerdo de su gloria, pues casi nada quedaba de aquella maravillosa colección [Todd, 2009: 182]

A pesar de todo, según Juan José Saldaña [2005: 22], la 
Independencia de México también motivó, casi inmediatamente, un aspecto positivo para el desarrollo científico del país:

[...] se produjo un movimiento de ideas, de intereses y una legislación para conseguir la creación de verdaderas instituciones científicas. La solución que se intentó estuvo basada en la organización pública de la actividad científica no sólo para usar el conocimiento científico, sino para crearlo y recrearlo en instituciones de investigación y docencia científicas republicanas [Saldaña, 2005: 22].

Sería hasta el triunfo de los liberales mexicanos que el avance científico en el país reiniciaría lentamente la marcha pausada durante los años de guerra. En diciembre de 1867, el gobierno de Benito Juárez promulgó la Ley Orgánica de Instrucción Pública, redactada en gran medida por Gabino Barreda, con la cual imprimió a la enseñanza pública el carácter de laica, gratuita y obligatoria; se reorganizaron las instituciones educativas y se crearon nuevas escuelas: la Escuela Nacional Preparatoria, el Observatorio Astronómico Nacional y la Escuela Nacional de Ciencias y Literatura; todas regidas bajo principios positivistas. Así inició un proceso de desarrollo científico y tecnológico que alcanzaría su punto cúspide durante el gobierno de Porfirio Díaz.

EL PORFIRIATO: EL PRIMER INTENTO POR INSTITUCIONALIZAR LA CIENCIA

El Porfiriato es un periodo que ha sido juzgado injustamente en la mayoría de los libros de historia. Generalmente, la imagen que se tiene de Porfirio Díaz es la de un mal gobernante, represor y autoritario. Sin embargo, es importante tener en cuenta la otra cara del personaje: Díaz construyó 
un sistema político en el que la autoridad del poder central finalmente acabó con décadas de inestabilidad política, al someter a los caudillos y poderes regionales brindó al país la tranquilidad necesaria para poder desarrollar políticas y acciones de alcance nacional y de largo plazo [Matute, 1979].

Varios de los principales estudiosos del Porfiriato han señalado que tuvo al menos tres etapas diferentes muy marcadas: el ascenso y consolidación; el auge y crecimiento; y la crisis del régimen.

La primera etapa consistió en el ascenso de Díaz a la presidencia y el sometimiento de todos los poderes y caudillos regionales que lo desafiaron. Fue un periodo marcadamente militarista que se apoyó en el ejército y en la vinculación con generales que lo acompañaron en sus rebeliones contra Benito Juárez y Sebastián Lerdo de Tejada, y que tuvieron un papel clave al hacerse cargo de las gubernaturas estatales y de las jefaturas de las zonas militares. En esa etapa afianzó el general un indiscutible poder nacional. Su gobierno fue altamente personalista y se apoyó en su habilidad para establecer y mantener amistades y lealtades que consolidaron una relación de patronazgo con sus fieles, para ello debilitó paulatinamente el poder de los gobernadores y mantuvo el equilibrio entre los poderes y las élites regionales [Guerra, 1988].

La segunda etapa del Porfiriato fue la de mayor esplendor del régimen y significó un marcado viraje respecto de la anterior. Si en la primera había predominado la política y el control de los hombres y de las armas, en la segunda el rumbo se encaminó en torno de la modernización e industrialización del país. Los actores decisivos ya no fueron los viejos generales, sino la brillante generación de intelectuales orgánicos y administradores del gobierno federal conocida como los Científicos. Este grupo fue capitaneado por José Yves Limantour y Justo Sierra, quienes se hicieron cargo de la definición y aplicación de políticas públicas modernizadoras 
y desarrollistas [Matute, 1979].

El grupo de los Científicos, formado por abogados, médicos e ingenieros educados en el extranjero e impulsores del positivismo, planteó una restructuración del sector educativo y consolidó la idea de que el avance científico está directamente relacionado con el desarrollo y el progreso económico; es el inicio del apoyo formal e institucional del Estado a la ciencia en México.

Durante los gobiernos de Díaz se crearon la Comisión Geográfico-Exploradora (1877); el Observatorio Meteorológico (1877), la Comisión Geológica (1886), el Instituto Médico Nacional (1888), el Instituto Geológico (1891), el Instituto Bacteriológico Nacional (1895), la Comisión Geodésica Mexicana (1899), el Instituto Bibliográfico Mexicano (1899), entre otros [Pérez, 2010]. Estas instituciones publicaban regularmente y plasmaban el interés de desarrollar la joven ciencia mexicana. Incluso cuando muchas de ellas sólo fueran portavoces de lo que al interior de las instituciones pasaba como el Anuario del Observatorio Nacional, los Anales y el Boletín del Instituto Médico Nacional o el Boletín del Instituto Geológico, otras fueron publicaciones ininterrumpidas durante periodos largos, como la Gaceta Médica de la Academia Nacional de Medicina y otras más que llegaron a tener casi el mismo prestigio que publicaciones extranjeras europeas [Carrillo, 2010].

Es importante mencionar el interés de la sociedad civil decimonónica mexicana en los temas del desarrollo científico, el cual se vio expresado mediante la creación de diversas sociedades científicas, entre las que destacan la Sociedad Científica "Leopoldo Río de la Loza" (1886), la Sociedad Científica "Alejandro Humboldt" (1886), la Sociedad Científica "Antonio Álzate" (1884), la Sociedad Mexicana de Geografía y Estadística, la Academia Nacional de Medicina (1864), la Sociedad Química (1849), la Sociedad Farmacéutica (1870), y la Academia de ciencias Exactas, Físicas y Naturales (1890), 
entre otras.

El efecto de estas acciones del régimen sobre la sociedad fue profundo. A pesar de las distintas opiniones y posturas que puedan tenerse respecto de este periodo de la historia nacional, la realidad es que fue en este momento cuando la investigación científica recobró el impulso perdido durante los conflictos del siglo XIX.

\section{LA INSTITUCIONALIZACIÓN DE LA CIENCIA DURANTE EL SIGLO XX}

El inicio de la Revolución en 1910, al igual que el proceso independentista, tuvo el efecto de aletargar el desarrollo científico y tecnológico del país durante los años que duró el conflicto e inclusive más allá de la finalización del mismo, ya que las condiciones en que dejó al país no resultaban favorables para la investigación. ${ }^{1}$

Recuperada la estabilidad política, los gobiernos posrevolucionarios intentaron reactivar el desarrollo de la ciencia y la tecnología. En 1930 se fundó la Academia Nacional de Ciencias, que tenía por objetivo agrupar a todos los científicos del país, y en 1935 se instituyó el Consejo de Educación Superior y de Investigación Científica.

La Universidad Nacional Autónoma de México inició el camino que la llevaría a ser la principal responsable de investigación y desarrollo científico en el país. Después de obtener la autonomía, la UNAM creó diversos institutos y dependencias con el objetivo de generar conocimiento para contribuir al desarrollo y solución de los problemas nacionales, dentro de los cuales se cuentan el Instituto de Investigaciones Sociales fun-

${ }^{1}$ Aunque la Revolución mexicana fue la mayor catástrofe demográfica en América del Norte desde el siglo xvi y tuvo un muy importante impacto económico, éste no alcanzó a constituir una destrucción total de la capacidad productiva del país. $\mathrm{Al}$ respecto se recomienda revisar Rajchenberg [1997] y Ordorica y Lezama [1993]. 
dado en 1930, le sucedieron el Instituto de Geografía (1934), el Instituto de Física (1938), el Instituto de Investigaciones Económicas (1940), el Instituto de Química (1941), el Instituto de Matemáticas (1942) y el Instituto de Geofísica (1949).

En 1935, el presidente Lázaro Cárdenas creó el Consejo Nacional de Educación Superior y de la Investigación Científica (Conesic), que tenía el objetivo de ordenar y coordinar a las instituciones que realizaban investigación así como a las de enseñanza superior, para formar a los profesionistas necesarios para el desarrollo material y cultural del país. Desde este organismo se fundó el Instituto Politécnico Nacional en 1936.

Además, con la llegada de los refugiados españoles hacia 1939-1940 se logró un enriquecimiento y consolidación de la comunidad intelectual y científica en México al crearse, con apoyo de Conesic, el Colegio de México en 1938.

En 1942, Conesic fue sustituida por la Comisión Impulsora y Coordinadora de la Investigación Científica (CICIC) que, a su vez, se convertiría en 1950 en el Instituto Nacional de Investigación Científica (INIC) y que tendría el objetivo de promover la coordinación e investigación científica nacional, así como servir de órgano de consulta del presidente de la República.

En 1958 se fundó la Asociación Nacional de Universidades e Institutos de Enseñanza Superior (ANUIES) y, un año después, la Academia de la Investigación Científica, actualmente llamada Academia Mexicana de Ciencias.

Posteriormente a 1968, el presidente Gustavo Díaz Ordaz solicitó al INIC preparar el estudio intitulado "Política Nacional y Programa de Ciencia y Tecnología”, en el cual se presentó la propuesta de que dicha institución fuera sustituida por un organismo que contara con mayores capacidades y ámbitos de acción. El presidente encomendó al licenciado Luis Echeverría Álvarez la creación de un órgano que coordinara la ciencia y la tecnología desde el gobierno [Pérez, 2005: 246]: 
el Consejo Nacional de Ciencia y Tecnología.

Conacyt fue fundado el 23 de diciembre de 1970 como un mecanismo de reconciliación entre el Estado y la comunidad de científicos e intelectuales en el país [Pérez, 2005: 250]. Desde entonces, ha contribuido a que los científicos mexicanos aumenten tanto en número como en campos de investigación. Durante los primeros veinticinco años de su existencia (1971-1995), el Consejo concedió un total de 92000 becas a estudiantes mexicanos. De esta cantidad, 24000 correspondieron a becas al extranjero, entre ellas, 9800 de doctorado y posdoctorado [Conacyt, 2003].

En 1974, Carlos Gual Castro, presidente de la Academia de la Investigación Científica (AIC), propuso la creación de la figura de Investigador Nacional, quien estaría en libertad para establecerse en cualquier estado de la república y en la institución de su preferencia, teniendo suficientes recursos para equipar su laboratorio u oficina y para contratar colaboradores. En aquel momento el proyecto no prosperó, pero la AIC nunca abandonó la idea. En 1983, bajo la direccion de José Sarukhán, la Asociación presentó una propuesta que en un año después se traduciría, mediante acuerdo presidencial de Miguel de la Madrid, en la fundación del Sistema Nacional de Investigadores (SNI), el 26 de julio de 1984.

\section{BIBLIOGRAFÍA}

Bernal, J. [1990], La ciencia en la historia, México, unam, Nueva Imagen, $693 \mathrm{pp}$.

Carrillo Farga, A. [2010], La Escuela Nacional de Medicina durante el porfirismo: forjadora de la modernidad y pilar de la Universidad Nacional, para el futuro UnAM, en línea, http://www.paraelfuturo.unam.mx/node/1132

Conacyt [2003], Informe General del Estado de la ciencia y la Tecnología, México, Conacyt. 
Delgado Cantú, G. [2004], Historia de México, legado histórico y pasado reciente, México, Pearson.

García-Colín, L. [2010], La ciencia y el Estado, México, unam. Garner, P. [2003], Porfirio Díaz del héroe al dictador, México, Edit. Planeta.

Guerra, François Xavier [1988], México, del antiguo régimen a la revolución, México, Fondo de Cultura Económica.

Izquierdo, J. J. [1958], La primera casa de las ciencias en México: el real seminario de minería, México, Ediciones Ciencia. Matute, Álvaro [1979], "A cien años, Porfirio Díaz", en Estudios de Historia Moderna y Contemporánea de México, Instituto de Investigaciones Históricas, UNAM.

Ntumbua, J. [2012], Las instituciones de la política científica en México, Tecnológico de Monterrey-Octavo Congreso Nacional y Cuarto Congreso Internacional de la Red de Investigación y Docencia sobre Innovación Tecnológica, consultado en: http://www.uasnet.mx/ridit/Congreso2007/ m3p17.pdf, 30 de mayo de 2012.

Ordorica, M. y J. Lezama [1993], "Consecuencias demográficas de la Revolución Mexicana", en El Poblamiento de México, tomo IV, México, Consejo Nacional de Población. Pérez Tamayo, R. [2005], Historia general de la ciencia en México en el siglo XX, Fondo de Cultura Económica.

[2010], Biblioteca Jurídica virtual del Instituto de Investigaciones Económicas UNAM [en línea], http://biblio. juridicas.unam.mx/libros/6/2873/17.pdf

Rajchenberg, E. [1997], "La industria durante la revolución mexicana", en Romero, E. (coord.), La industria mexicana y su historia, México, UNAM.

Retana Guiascón, Ó. [2009], "La institucionalización de la investigación científica en México. Breve cronología, Revista Ciencias, núm. 94, abril-junio 2009, en línea, www. ejournal.unam.mx/cns/no94/CNS094000009.pdf

Saldaña, Juan José [2005], La casa de Salomón en México. Estudios sobre la institucionalización de la docencia y la 
investigación científicas, México, UnAM, $410 \mathrm{p}$.

Todd, L. [2009], Breve historia de la ciencia en México, Colegio de Estudios Científicos y Tecnológicos del Estado de Nuevo León, México, p. 182

Trabulse, E. [2003], Historia de la ciencia en México. Estudios y Textos, México, Fondo de Cultura Económica. 


\title{
ACTORES DE LA CIENCIA
}

\author{
Yolanda Ham Zarco* \\ Carlo Daniel Pineda**
}

\section{LAS UNIVERSIDADES: PROTAGONISTAS DE LA INVESTIGACIÓN NACIONAL}

Posteriormente a la creación del Consejo Nacional de Ciencia y Tecnología (Conacyt), la ciencia y la tecnología, como parte fundamental del desarrollo de un país, no fueron consideradas de alta prioridad en la agenda de los sucesivos gobiernos ni de la industria o de la sociedad en general. Fue en la educación superior donde la ciencia sí pudo desarrollarse. Algunas universidades abrieron sus aulas a un elevado grado de especialización sin otra finalidad que la de buscar respuestas a los fenómenos naturales y a los problemas de la sociedad. De esta forma, la academia desempeñó y sigue desempeñando un papel fundamental en la creación, desarrollo y difusión de la investigación científica en México, buscando la conexión entre la universidad y la sociedad para el mejoramiento de las condiciones de vida de la ciudadanía.

La institucionalización de la ciencia en México ha sido un proceso gradual. Se inicia durante la década de 1950 y ha

* Egresada de la carrera de Sociología de la Facultad de Ciencias Políticas y Sociales de la UNAM y becaria del proyecto PAPIIT IN302410.

** Egresado de la licenciatura en Relaciones internacionales, becario del proyecto PAPIIT IN302410 y actualmente se desempeña como asistente de investigación en el Instituto de Investigaciones Sociales de la UNAM. 
contribuido a la profesionalización de los procesos de investigación. Al promover y patrocinar los proyectos de investigación y las becas dentro y fuera del país, el Estado ha financiado el desarrollo científico con el propósito de lograr el progreso económico y social del país. En el contexto histórico de 1950 la economía de la nación se operaba mediante el modelo de sustitución de importaciones o de desarrollo hacia dentro. La investigación científica era considerada uno de los pilares del progreso nacional.

En este capítulo se explica cómo han influido las instituciones de educación superior y los institutos de investigación (en sus diversas y múltiples modalidades) en la profesionalización de la ciencia mexicana, centrándose en las universidades públicas, que es donde se registra el mayor número de proyectos de investigación en la actualidad.

Es importante señalar que la institucionalización de la ciencia y la tecnología en México, así como su desarrollo y difusión, ha tenido como centro a la Ciudad de México, debido a la concentración de los tres poderes de gobierno y de las principales instituciones académicas vinculadas con la ciencia y tecnología en este espacio geográfico. En este sentido, en 1968, 80\% de la investigación científica y tecnológica nacional se desarrollaba en el Distrito Federal [Conacyt, 2003] y, principalmente, en la Universidad Nacional Autónoma de México (UNAM). En consecuencia, dicho proceso de centralización, requiere que las actividades académicas se incentiven en otras partes de la República.

Actualmente, las universidades públicas y los institutos nacionales localizados en el Distrito Federal generan casi 50\% de la investigación científica del país, y la UNAM contribuye con $35.2 \%$ del total nacional. Suman 3404 los investigadores residentes en la Ciudad de México afiliados al Sistema Nacional de Investigadores (SNI) (21.9\% del total de miembros); seguido por el Instituto Politécnico Nacional (IPN) con $6.7 \%$ de las investigaciones y 676 miembros del SNI (4.3\%); mientras 
que la Universidad Autónoma Metropolitana (UAM) genera $6.4 \%$ de la investigación científica, pero se encuentra por arriba del IPN en cuanto al número de miembros del SNI con 837 (5.4\%). Por otro lado, la Universidad de Guadalajara (U de G) se encuentra en cuarto lugar con $3.5 \%$ del total de la investigación y con 607 miembros del sNi; la Universidad Autónoma de Nuevo León (UANL) con 2.8\% y 393 afiliados, y la Benemérita Universidad Autónoma de Puebla con 343 miembros del SNI. Estas universidades suelen considerarse como algunas de las más importantes de la República mexicana.

Tabla 1

Investigadores por cada 100000 habitantes

(2013)

\begin{tabular}{lclc}
\hline \multicolumn{1}{c}{ Entidad } & Tasa & \multicolumn{1}{c}{ Entidad } & Tasa \\
\hline Distrito Federal & 80.1 & Coahuila & 10.3 \\
Morelos & 50.6 & Sinaloa & 10.22 \\
Baja California Sur & 33.9 & Tlaxcala & 9.83 \\
Querétaro & 26.6 & Aguascalientes & 9.62 \\
Yucatán & 23.8 & Chihuahua & 9.04 \\
Colima & 23.4 & Hidalgo & 8.97 \\
Baja California & 19.4 & Ouintana Roo & 8.3 \\
Promedio Nacional & 17.5 & Nayarit & 8.11 \\
San Luis Potosí & 17.2 & Veracruz & 7.65 \\
Nuevo León & 16.6 & Edo. de México & 7.27 \\
Sonora & 15.8 & Durango & 7.23 \\
Jalisco & 13.6 & Oaxaca & 6.21 \\
Michoacán & 13.1 & Tabasco & 4.96 \\
Puebla & 12.8 & Tamaulipas & 4.96 \\
Guanajuato & 12.4 & Chiapas & 4.25 \\
Campeche & 12.3 & Guerrero & 2.27 \\
Zacatecas & 11.2 & & \\
\hline
\end{tabular}

Fuente: Foro Consultivo de Ciencias. 
La universidad más antigua de México fue la Real y Pontificia Universidad de México, fundada en 1551 bajo el mandato del Rey Carlos de España, más conocido como Carlos V. El papa Clemente VIII le otorgó el rango de pontificia en 1595. Sus estatutos fueron iguales a los de la Universidad de Salamanca y su método de enseñanza se basaba en la filosofía escolástica. Las principales autoridades eran Santo Tomás de Aquino y Aristóteles.

Después de la Independencia de México, debido a las transformaciones de la sociedad, la Universidad fue cerrada y se mantuvo así durante la mayor parte del siglo xIx. Se refundó como Universidad Nacional el 24 de abril de 1910, gracias al impulso dado por el entonces secretario de Educación, Justo Sierra. Su refundación como Universidad Nacional de México respondió a intereses políticos que intentaban crear una institución laica que formara a los científicos que el país necesitaba para incorporarse a los países más avanzados de la época; a la vez que mostraba la fortaleza de México como nación independiente.

Interviene el periodo revolucionario y es hasta 1929 que se declara la autonomía que significa la independencia de la Universidad, que anteriormente dependía administrativamente de la Secretaría de Educación del gobierno federal. En 1945 el rector Alfonso Caso, distinguido arqueólogo mexicano, dotó a la UNAM de la Ley Orgánica que es el estatuto que actualmente la rige. En 1954 se inaugura la Ciudad Universitaria que es el campus principal de la Universidad.

Las nuevas instalaciones permitieron la expansión de la UNAM con la creación de institutos de investigación, que favorecieron la formalización de la investigación en tanto que se impulsó el desarrollo de disciplinas científicas por medio de la cooperación y el trabajo entre investigadores-profesores y estudiantes. Se puede ubicar el inicio de este proceso con 
la creación de los Consejos Técnicos junto con la codificación de la figura del investigador en la Ley Orgánica de 1945. La profesionalización de la ciencia centralizó todas las actividades de docencia e investigación con las condiciones e infraestructura necesarias para tal propósito.

Actualmente, la UnAm cuenta con 36750 académicos, los cuales imparten 40 programas de posgrado con 87 planes de estudio de maestría y doctorado, 99 licenciaturas y 22 carreras técnico profesionales. Cuenta con 13 facultades, siete unidades multidisciplinarias y cuatro escuelas; 30 institutos de investigación, 16 centros y nueve programas universitarios, en los cuales laboran 3624 académicos miembros del SNI. Alrededor de 35\% de los artículos científicos publicados por científicos mexicanos corresponden a investigadores de la UNAM. ${ }^{1}$

El doctor Ruy Pérez Tamayo expresa así la importancia de la Universidad:

En la historia de la ciencia en México en el siglo xx, la UnAM ocupa desde luego el sitio más importante. Surgida en las postrimerías del Porfiriato como una estructura endeble y más bien administrativa que académica, la Universidad Nacional se constituyó gracias a la incorporación de varias instituciones científicas y docentes que ya existían aisladas desde la segunda mitad del siglo XIX [...] Los primeros años de la Universidad fueron azarosos, e incluso llegó a estar al borde de desaparecer en más de una ocasión. Pero a pesar de sus muchos problemas, tanto iniciales como a lo largo de toda su historia, en el transcurso del siglo pasado, la UNAM se transformó de una pequeña oficina burocrática con mínima influencia en la escasa investigación que se hacía entonces en otras dependencias, en el principal centro científico académico no sólo de México sino de toda América Latina [...] pero todavía a fines del siglo Xx la UNAM sola tenía más institutos de investigación y más investigadores

\footnotetext{
${ }^{1}$ Estadística disponible en http://www.estadistica.unam.mx/numeralia/
} 
que todas las demás instituciones académicas del país juntas, y generaba más del $65 \%$ de toda la producción científica del país [Pérez, 2005].

En conclusión, la Universidad Nacional Autónoma de México es emblemática en el proceso y concreción de la institucionalización de la ciencia en México, gracias a las actividades realizadas tanto internas como externas y su esfuerzo constante de hacer ciencia.

CENTRO DE INVESTIGACIÓN Y DE ESTUDIOS AVANZADOS DEL INSTITUTO POLITÉCNICO NACIONAL (CINVESTAV)

En 1939 los ingenieros Luis Enrique Erro y Carlos Vallejo, así como el licenciado Narciso Bassols, idearon integrar un sistema de enseñanza técnica que nació cuatro años después gracias a la participación del senador Juan de Dios Bátiz y al presidente Lázaro Cárdenas del Río. El general Cárdenas se propuso llevar a cabo los anhelos de la Revolución mexicana en materia educativa y para lograrlo dio nacimiento al Instituto Politécnico Nacional (IPN).

El IPN no fue pensado exclusivamente como una casa de estudios, sino que también sería el origen de un gran número de proyectos científicos. Esto dio como resultado la posterior creación del Centro de Investigación y de Estudios Avanzados (Cinvestav). Dicha institución se creó en 1961 por decreto presidencial como un organismo público descentralizado con personalidad jurídica y patrimonio propios, dependiente de la Secretaría de Educación.

El Cinvestav inició sus trabajos sin casa propia, con seis profesores y con sólo cuatro departamentos: fisiología, física, matemáticas e ingeniería. Para 1968 la institución ya tenía sus 
primeros edificios (inaugurados en 1965), la mejor biblioteca científica de América Latina y 37 profesores distribuidos en siete departamentos. Su presupuesto anual había crecido de un millón de pesos en 1961, a 16.7 millones de pesos en 1968 (pero desde 1966 ya no había aumentado), y su producción académica, tanto en publicaciones científicas del más alto nivel, como en número y calidad de estudiantes graduados sólo era superada en México por la UNAM. En el año 2000, el Cinvestav tenía 568 profesores distribuidos en 17 departamentos y cinco unidades descentralizadas (Mérida, Saltillo, Guadalajara, Querétaro y Distrito Federal), había graduado 2946 maestros y 841 doctores [Pérez, 2005].

La institución tiene como bases la incorporación de recursos humanos altamente calificados, nacionales o extranjeros; una remuneración adecuada al trabajo científico que se realice, la obligación de proveer de todos los insumos materiales o humanos necesarios para el fin de la investigación y la independencia absoluta para tratar todos las problemáticas que se quieren estudiar. De esta forma, Cinvestav cuenta con el apoyo del IPN, del gobierno federal y otras instituciones que contribuyen al enriquecimiento de la investigación científica mexicana a través de este centro.

\section{UNIVERSIDAD AUTÓNOMA METROPOLITANA (UAM)}

El origen de la UAM se remonta a la necesidad de redistribuir y satisfacer las demandas de la población joven de la Ciudad de México que quería ingresar en la educación superior pero que no lograba obtener un lugar en la UNAM o en el IPN debido a la alta demanda que enfrentaban dichas instituciones. Desde su fundación en 1974, la estructura de la UAM fue desarrollada como una universidad "multicampus" en donde se podía alojar al exceso de población estudiantil que era 
constantemente rechazada (para 1973, de 180000 solicitudes de ingreso, la UNAM sólo pudo atender a 40000 y el Politécnico tan sólo a 28 000) debido a las limitaciones de infraestructura y de docencia que experimentaban. Por este motivo:

[...] se hacía notar que al tener varios campus podían establecerse diferentes modelos académicos, dentro de los lineamientos comunes [...], y lograr así una diferenciación y una competencia sana que resultarán positivas. Igualmente, se señalaba que la oferta académica de la Universidad, en su conjunto, podía ser muy amplia y cubrir todas las disciplinas y campos profesionales, conservando un tamaño adecuado de cada Unidad; que algunos recursos o instalaciones muy costosas podrían compartirse y que, al existir Unidades en distintos rumbos de la ciudad, se podría ayudar al desarrollo social y cultural de estos rumbos, que eran zonas marginadas, ya que sólo en ellas se encontraban terrenos de las dimensiones requeridas [López, 1998: 236].

Así, atendiendo a las necesidades económicas y geográficas de la Ciudad de México durante la década de los años setenta, se lograron establecer los tres campus actuales de la UAM: Azcapotzalco, Iztapalapa y Xochimilco, cada una de las cuales ofrecía carreras afines a la zona geográfica en que se había establecido. Por consiguiente:

Azcapotzalco se ubicó en una zona industrial, de las más importantes del país, abrió carreras de tipo profesional aplicado, con énfasis en las ingenierías [...]. Se esperaba de esta Unidad una fuerte vinculación con la industria.

La Unidad Iztapalapa se enfocó hacia las ciencias básicas y las humanidades. Aunque su ubicación no se relaciona directamente con estas disciplinas, sí quedaba relativamente cerca de los institutos de investigación de la UNAM con los que se esperaba una vinculación importante.

Se pensó que la Unidad Xochimilco daría prioridad a las carreras relacionadas con el sector salud. Por eso se ubicó relativamente cerca del área de grandes hospitales en el sur de la 
Ciudad de México [López et al., 2000: 237-238].

La subdivisión de la estructura académica de la UAM respondía a la necesidad de crear nuevos esquemas de vinculación entre la docencia y las actividades de investigación por medio de las siguientes figuras:

[...] La Unidad Universitaria es una organización en Divisiones y Departamentos instituida para cumplir el objeto de la Universidad dentro del régimen de desconcentración funcional y administrativa [...] El Departamento es una organización académica básica de las Divisiones constituida fundamentalmente para la investigación en disciplinas específicas o en conjuntos homogéneos de éstas, así como para desarrollar actividades de docencia en esas disciplinas de acuerdo con los planes y programas académicos de las diversas Divisiones que integran la Universidad. Un área es una organización dentro de los Departamentos que se ocupa fundamentalmente, o cuyo propósito es ocuparse, del desarrollo de proyectos de investigación en una especialidad o en especialidades afines [López, 1998: 253].

A pesar de existir una disposición para vincular tanto a la docencia como a la investigación, en un primer momento se dio prioridad a las actividades de investigación; a partir de la primera mitad de la década de los años ochenta se prefirió encontrar un equilibrio entre éstas y la docencia, debido a la necesidad de otorgar nuevas plazas a los jóvenes estudiantes que deseaban ingresar en una carrera y eran rechazados en la UNAM y el IPN.

La institucionalización del conocimiento no solamente corresponde a la vinculación entre elementos abstractos tales como las relaciones entre el Estado, la academia y la sociedad sino que además, para constituirse en un modelo eficiente, necesitó ser dotada de una variable geográfica, la cual determinó, en mayor o menor medida, la manera en que dichas Unidades 
académicas funcionaban no sólo para fortalecer el papel de la ciencia en el Estado, sino que en el caso de la Universidad Metropolitana sirvió, al menos en un primer momento, como apoyo a necesidades de las distintas zonas urbanas (es decir, de las necesidades locales) del Distrito Federal.

Una de las principales preocupaciones se centró en la capacidad de vincular a la docencia y la investigación en un modelo parcialmente descentralizado. Por ello, la UAM fue subdividida en Divisiones y Departamentos Académicos que tienen a su vez la figura del profesor-investigador. A partir del año de 1982, con la aprobación del reglamento de Ingreso, Promoción y Permanencia del Personal Académico, se estableció que: "El personal académico de carrera realizará fundamentalmente las funciones de docencia e investigación, sin excluir la función de preservar y difundir la cultura" [López, 1998: 243].

Sin embargo, la estructura académica de la UAM entraba en conflicto con las estructuras tradicionales de instituciones tales como la UNAM y el IPN. Por esta razón, el Departamento Académico fue definido como: "[...] una unidad básica administrativa, que reúne a una comunidad de profesores e investigadores, relativamente autónoma y responsable de la docencia y la investigación, en un campo especializado del conocimiento" [López et al., 2000: 244]. Por otra parte, en cuanto a los esfuerzos de divulgación de la ciencia, la Coordinación General de Difusión de la Universidad Metropolitana, al igual que otras universidades, ha trabajado para desarrollar proyectos de divulgación científica para todo el público que puedan ser consultados por medio de internet.

Por consiguiente, dentro de los esfuerzos más importantes de la institución se encuentran programas como "La Metro en el Metro: Un paseo por el conocimiento”, divulgación de actividades científicas en el Sistema de Transporte Colectivo Metro; "El mes de la ciencia y la tecnología", talleres y actividades de divulgación; "La ciencia en las calles", divulgación 
en vías públicas junto con el Instituto de Ciencia y Tecnología del Distrito Federal (IсутDF) y "Platicando sobre ciencia", charlas de divulgación realizadas en diversos lugares de la Ciudad de México. Además, se ha desarrollado una estrecha vinculación con este Instituto para crear nuevas oportunidades para el financiamiento de proyectos realizados por estudiantes y profesores-investigadores, con el propósito de generar y aumentar el número de patentes que puedan ser transferidas a la industria o directamente al gobierno, que se reflejen en resultados tangibles para la sociedad. Por consiguiente, uno de los objetivos centrales de dicha cooperación se basa en crear nuevas modalidades para la protección de la propiedad intelectual, las cuales a su vez generen nuevos puestos de trabajo y contribuyan al mejoramiento del nivel de vida de las comunidades.

\section{UNIVERSIDAD AUTÓNOMA DE GUADALAJARA (UAG)}

Fue fundada en 1925, cuando se expide su primera ley orgánica basada en cuatro pilares: mejorar los servicios de educación en aspectos administrativos y docentes, planificar la enseñanza industrial y agrícola, reorganizar la enseñanza elemental y establecer las escuelas y dependencias que hacían falta para la total integración de la enseñanza superior. Posteriormente, la Ley Orgánica de 1937 incluye un aspecto fundamental para los fines de la UAG que no había sido considerado en la primera Ley: la investigación científica, en donde los planes y programas de estudio obedecerían al principio de la identidad esencial de los diversos fenómenos del universo.

En consecuencia, la UAG estableció seis líneas estratégicas de acción: la innovación educativa, la investigación, la internacionalización, la extensión, la gerencia y el gobierno. A pesar de la existencia de grupos de investigación, el impulso a la investigación en la institución provino de élites internas, 
por lo que la expansión de la investigación se inició verdaderamente con la creación del Departamento de Intercambio Académico en el año de 1979, que es un órgano de enlace de la Universidad con el resto de las universidades y comunidades académicas, nacionales y extranjeras, pero también es una instancia destinada a captar apoyos para el desarrollo de las diversas funciones sustantivas de la UAG.

Por otro lado, dentro del Departamento de Intercambio Académico se creó una Coordinación de Apoyo a la Investigación que se convirtió en la primera instancia formal para el estímulo y el desarrollo de esta actividad. En 1983 el Departamento de Intercambio Académico se transformó en el Departamento de Investigación Científica y Superación Académica (DICSA), el cual generó una política más clara de fomento a la investigación, como fueron las negociaciones que propiciaron la aparición de condiciones adecuadas para la docencia, la contratación de personal por tiempo completo o medio tiempo, lo cual derivó en el incremento de la planta de investigadores, pasando de 15 en 1983, a 500 en 1994. Sin embargo, sólo una pequeña parte de ellos pertenecen al SNI. Por esta razón, en el 2000 la UAG apenas contaba con 149 afiliados al SNI [Chavoya, 2002].

\section{UNIVERSIDAD AUTÓNOMA DE NUEVO LEÓN (UANL)}

Fue oficialmente inaugurada en 1933; no obstante, hasta 1971 se promulga la cuarta Ley Orgánica, por la que se le concede su autonomía, tomando el nombre de Universidad Autónoma de Nuevo León (UANL). Realiza 2.8\% del total de la investigación científica en el país, en este sentido, su mayor contribución a la institucionalización proviene de la formación del Instituto de Investigaciones en 1943, que se convirtió en la Dirección de Investigación en 2010, y que tiene la misión de promover y fomentar la investigación científica y 
tecnológica ligada a los recursos humanos y a los programas de posgrado de la propia Universidad para generar un nuevo polo de desarrollo científico y tecnológico.

La UANL tiene más de 390 investigadores registrados en el SNI y 400 profesores, por lo que es la universidad más importante en investigación del noreste del país. La UANL posee 27 centros de investigación y 84 bibliotecas. Además, publica más de diez revistas especializadas en diferentes áreas de conocimiento. En 2008 se publicaron 471 trabajos de investigación en revistas científicas de circulación nacional e internacional y se llevaron a cabo 45 trámites para registro de patentes.

BENEMÉRITA UNIVERSIDAD AUTÓNOMA DE PUEBLA (BUAP)

Quedó legalmente instituida el 4 de abril de 1937, pero es hasta 1956 que logra su autonomía. La BUAP es el principal polo de investigación científica y cultural de todo el estado de Puebla: 343 de sus investigadores pertenece al sNI, lo que la ubica en el sexto lugar nacional.

Por otro lado, la fundación del Instituto de Biología y Medicina Experimental en 1958 y su restructuración en 1963, así como los indicios de la investigación en la escuela de Físico Matemáticas, son los antecedentes de lo que sería más tarde el Instituto de Ciencias de la Universidad Autónoma de Puebla (ICUAP), que es una unidad académica fundada en 1974, con la finalidad de reorganizar, coordinar y promover la investigación científica a partir de los recursos de la Universidad, que se encontraban dispersos en distintas escuelas.

UNIVERSIDAD MICHOACANA DE SAN NICOLÁS DE HIDALGO (UMSNH) 
Fue establecida el 15 de octubre de 1917. Empero, su Ley Orgánica fue promulgada hasta el 14 de febrero de 1933, la cual, en su artículo $2^{\circ}$, le asignó la responsabilidad de organizar la investigación científica, aunque no se marcó la estructura que debería tener la institución para promover dicha actividad. La nueva Ley de 1961 incluyó un capítulo especial para la creación y funcionamiento del Consejo de la Investigación Científica, al cual se le encomendó las labores de fomento, desarrollo y coordinación de la investigación y de sus aportaciones, estableciendo de manera precisa la organización de Institutos y Departamentos especializados en las diversas ramas de las ciencias y las humanidades.

Esta ley también estableció la existencia de la Coordinación de la Investigación Científica como dependencia encargada de ejecutar los acuerdos del Consejo y la integración del titular de la Coordinación al Consejo Universitario, declarado como máxima autoridad de la institución. Por lo tanto, la Universidad Michoacana se sustentó en la creación de centros e institutos de investigación, además de la agrupación de los profesores adscritos a las escuelas y facultades. La institución tiene una importante planta de investigadores de reconocida trayectoria académica, adscrita principalmente a los ocho institutos y cinco centros de investigación.

\section{UNIVERSIDAD AUTÓNOMA DE LA CIUDAD DE MÉXICO (UACM)}

Desde su inauguración en el año 2001, la UACM fundó diversos centros de investigación especializados. Sin embargo, estos centros han logrado limitados avances en cuanto a la vinculación entre docentes y alumnos, a pesar de que entre sus objetivos se destaca la tarea de "estimular el trabajo de investigación vinculado a la docencia y a la generación de conocimientos que brinden soluciones a la sociedad"; pese a 
esto, en el plano estrictamente formal, no existen indicadores que puedan respaldar de manera convincente la eficiencia y el funcionamiento adecuado de tales instituciones.

Aun cuando la UACM cuenta con toda una estructura orgánica para determinar la validez, duración, financiamiento y evaluación de los proyectos de investigación, es importante mencionar que la cantidad de ayudas e incentivos para realizar dichos emprendimientos es relativamente limitada en cuanto a financiamiento general, además de la ausencia de estadísticas o mecanismos de medición de la eficiencia y los resultados, que puedan aportar pruebas objetivas sobre la calidad y el desarrollo de la investigación científica en esta institución.

Por lo tanto, es posible concluir que la UACM, a pesar de contar con los organismos y leyes adecuadas para favorecer las actividades antes mencionadas, actualmente no ha logrado alcanzar todo su potencial.

La UACM ha desarrollado mecanismos de difusión internos que se destacan por su amplia variedad de temáticas. En este sentido, la Universidad desarrolló durante el año 2011 la revista electrónica Acércate (http://www.uacm.edu.mx/ RevistaAcercate/), mediante la cual publica artículos sobre ciencia y tecnología. También mantiene el programa: "Jueves de Ciencia y Tecnología” por medio del cual se realizan actividades de divulgación en las áreas de investigación prioritarias para la institución, así como los "Seminarios de Informática”; "Ciencia y Sociedad"; "Café y Matemáticas"; "Hablemos de Investigación” y "Seminarios de Física”, en donde se convoca a la participación de estudiantes y académicos.

Después de este brevísimo recorrido histórico por las múltiples instituciones públicas de educación superior que han aportado a la institucionalización de la ciencia en México, se puede apreciar como han sido motores fundamentales para el desarrollo de la ciencia y la tecnología nacionales. 


\section{BIBLIOGRAFÍA}

ANUIEs [2012], Anuario estadístico 2011 de la Asociación Nacional de Universidades e Instituciones de Educación Superior, México, ANUIES.

Castro, S. [2012], Rendimientos de la Investigación Científica, en línea, http://www.eveliux.com/mx/rendimientos-de-lainvestigacion-cientifica.php,20/06/2012.

Chavoya Peña, M. L. [2002], "La expansión de la investigación en la Universidad de Guadalajara: límites y desafíos", ponencia presentada durante el $10^{\circ}$ Congreso internacional: Retos y expectativas de la Universidad, Universidad de Guadalajara, México.

CICESE [2003], Anuario 2002 del Centro de investigación científica y de educación superior de Ensenada, Conacyt, México. Conacyt [2003], Informe General del Estado de la Ciencia y la Tecnología, México, Conacyt.

López Zárate, R. et al. [1998], Una historia de la UAM. Sus primeros 25 años, UAM, México, vol. I, cap.VI "La organización académica", pp. 235-256.

López Zárate, R., M. Á. Casillas Alvarado y O. M. González Cuevas [2000], Una historia de la UAM: sus primeros 25 años, México, UAM.

Pérez Tamayo, R. [2005], Historia general de la ciencia en México en el siglo $x x$, Fondo de Cultura Económica. unam [2013], Agenda estadistica 2013, México, unam. 


\title{
EL ESTADO EN EL DESARROLLO CIENTÍFICO DEL SIGLO XX
}

\author{
Erandi González Alamilla*
}

Lo que ocurre en la mente de cada científico, en el interior de un laboratorio o sobre un escritorio es diferente según el contexto. La ciencia es un producto social, derivado de la necesidad de racionalizar y acotar el entorno; ${ }^{1}$ es el reflejo de un animal racional, que para comprender su condición y existencia requiere sistematizar las situaciones, acciones y reacciones para crear modelos que le permitan, en la medida de lo posible, asimilar las múltiples respuestas que se obtienen cada que algo varía. La ciencia es el mecanismo del ser humano contra la incertidumbre de su individualidad y de su entorno.

Todo el tiempo hay científicos acotando la incertidumbre, por eso, en la actualidad, las aportaciones de quienes participan en el ámbito científico suelen develar información diminuta respecto del universo de posibilidades, pero valiosa para reducir la incertidumbre en su área. La información obtenida suele estar restringida a las condiciones desde las cuales se obtuvo, por lo tanto, se ha vuelto indispensable para validar la certeza de esa información nueva que el científico

* Maestra en Administración y Políticas Públicas por el Centro de Investigación y Docencia Económicas A.C.

${ }^{1}$ Bungue [2005/1976], expone la construcción de un conocimiento sistematizado, convertido en un conjunto de ideas al que se denomina como ciencia. 
la contextualice con la mayor precisión posible (acotando con precisión la metodología y herramientas utilizadas) [Adcock y Collier, 2001].

Los sistemas de gobierno han sido un factor contextual determinante en la producción de información o en la posibilidad de que ésta sea validada, en especial cuando llegó la etapa de globalización del conocimiento. Los individuos que se habían especializado en el ámbito científico en un entorno, tenían que ser equivalentes a quienes se habían formado en otro, por lo tanto, en la medida que alguno de los entornos no favoreciera al individuo, éste se vería rezagado respecto de los demás. Los gobiernos de cada país aprueban legislaciones enfocadas a las áreas que cada sociedad considera deseables o de interés público, ${ }^{2}$ entre esas legislaciones algunas impactan en la disponibilidad de los recursos económicos del país, en la forma de obtener tales recursos; y otras, en la forma de distribuirlos. Así, las leyes afectan las decisiones de los individuos para formarse como científicos, porque de ellas dependen las posibilidades de optimizar su ingreso, ser reconocido y tener los instrumentos para validar sus descubrimientos.

De acuerdo con lo anterior, las políticas que el gobierno implementa en materia científica son un reflejo de la ideología de la sociedad y de los intereses del Estado. Dado que el contexto social impacta en las creencias del individuo y éste, a su vez, es capaz de afectar su contexto, las ideologías sociales son un proceso que está en constante modificación. ${ }^{3}$ El gobierno, para legitimarse, tiene que entrar en el proceso e

${ }^{2} \mathrm{El}$ interés público entendido desde la teoría normativa: una norma ética para la evaluación de políticas públicas específicas y una meta que el orden político debe perseguir. Por lo tanto, es necesario asumir que el interés público está relacionado con el bien común, la razón de la asociación de los individuos, el logro de objetivos comunes a todos (Schubert y Sorauf en Cochran [2010/1974]).

${ }^{3}$ Simon [1997/1947] señala que un individuo está cargado de valores, creencias, ideales y objetivos, estos individuos al organizarse crean un contexto, el cual puede modificar, posteriormente, a los individuos, quienes, a su vez, volverán a impactar en la modificación del contexto. 
interactuar con los diferentes grupos que luchan por que sus ideas tengan un espacio en la agenda política y gubernamental del país [Arellano, 2012]. En este sentido, resulta interesante preguntar cómo ha sido el proceso de construcción de la ideología científica en México y cuál es el papel que ha desempeñado el gobierno como el principal actor en el modelado del contexto para el desarrollo de la ciencia.

Hablar del papel del Estado mexicano en los temas científicos durante el siglo xx es hablar de la construcción directa o indirecta de una ideología académica, parteaguas para las oportunidades de desarrollo profesional de los mexicanos. Tras los primeros veinte años del siglo pasado, inició un proceso de aprendizaje tanto para el gobierno como para la sociedad en general. Sin embargo, ese proceso no fue al mismo ritmo para ambas partes, lo que provocó que unos no obtuvieran lo que esperaban de los otros. Este breve texto pretende mostrar las principales acciones del gobierno que tuvieron un impacto -positivo o no- en el desarrollo científico del país durante las décadas de 1920 a 2000.

\section{EL ESTADO POSREVOLUCIONARIO}

La literatura versada en la historia de México permite identificar tres situaciones clave que modificaron la ideología de los mexicanos, así como el actuar del gobierno respecto de la educación y la percepción de la ciencia, a saber, la Revolución mexicana, la migración del campo a la ciudad y la inmigración de personas con preparación científica y tecnológica. Por un lado, la Revolución mexicana dejó tras su paso una ola de aprendizaje respecto del uso de productos industrializados, como los ferrocarriles o telégrafos. Por otro lado, la migración del campo a la ciudad incrementó la población de estas últimas, provocando que el gobierno generara nuevas opciones educativas. Finalmente, los disturbios sociopolíticos de 
Europa trajeron al país a muchos refugiados gracias a las políticas de apertura existentes, entre esos refugiados se encontraban personas con preparación científica superior a la que existía en ese momento en México.

La década posrevolucionaria estuvo presidida por tres personajes: Álvaro Obregón (1920-1924), Plutarco Elías Calles (1924-1928) y Emilio Portes Gil (1928-1930). Además de las actividades militares y económicas que desarrollaron en sus respectivos periodos, cada uno de ellos aportó algo a la promoción del conocimiento: Obregón, en colaboración con José Vasconcelos, fundó la Secretaría de Educación Pública, una dependencia de Estado cuya principal función sería institucionalizar la educación federal y articular el proceso educativo; acciones derivadas de esto fueron el apoyo a escuelas rurales, la edición de libros de texto gratuitos y el impulso a la educación media superior [Irigoyen, s/f]. Calles, por su parte, impulsó la creación de escuelas rurales y la apertura de universidades y los primeros institutos técnicos [León, 1975]. Portes Gil, con una visión más economista, tuvo que enfrentarse a la huelga estudiantil de 1929, la cual, a diferencia de los movimientos militarizados revolucionarios, estaba compuesta de estudiantes organizados; la solución que el gobierno dio fue otorgar la autonomía a la Universidad Nacional para controlar las demandas de la nueva comunidad estudiantil [Marsiske, s/f].

\section{LA CONSTRUCCIÓN DE LA IDEOLOGÍA CIENTÍFICA: UN PROCESO DELIBERATIVO}

La siguiente década, una de las más significativas para el desarrollo científico del país, estuvo dividida en dos partes: por un lado, los gobiernos de Pascual Ortiz Rubio (19301932) y Abelardo L. Rodríguez (1932-1934) que continuaron con la dinámica de los presidentes anteriores en materia de 
educación rural. Por otra parte, la llegada a la presidencia de Lázaro Cárdenas (1934-1940) y su visión tecnificadora de la población.

Cárdenas realizó, en materia de ciencia, diferentes actividades en su mayoría orientadas a incrementar la población capacitada y especializada en los principales sectores de producción. Entre ellas: declaró como socialista el carácter de la educación, por medio del artículo $3^{\circ}$ constitucional; en 1935 instituyó el Consejo Nacional de la Educación Superior y la Investigación Científica (CNESIC); en 1936 inauguró el Instituto Politécnico Nacional; en 1937 consintió la creación del Instituto Nacional de Educación Superior para Trabajadores; modificó la Ley Orgánica de la UNAM, para restringir su autonomía; promovió la creación de centros universitarios descentralizados y el financiamiento de universidades e instituciones de educación superior ubicadas fuera del área metropolitana [Gutiérrez, 2009]. Todas las actividades en el ámbito científico desarrolladas por Cárdenas estuvieron sujetas a los mandatos asignados por medio del CNESIC; una vez que el sexenio llegó a su fin, el Consejo también lo hizo.

Es preciso resaltar que esta etapa gubernamental de México sirvió indirectamente para fortalecer la ideología de la Universidad Nacional Autónoma de México (UNAM), pues aprendió a crear con el gobierno un diálogo académico, argumentativo y pacífico. Durante el gobierno cardenista, la empresa privada no era un actor relevante para la construcción de la sociedad consciente, en cambio, tanto el Estado como la academia se encontraban en constante interacción por medio del diálogo; ambos estaban aportando ideas y acciones para el mejoramiento social, cada uno con los instrumentos que tenía a su disposición.

Otro ámbito que modificaría las posibilidades del quehacer científico fue el apoyo del gobierno cardenista al área de investigación en biomedicina. En 1939, fundó el Instituto de Salubridad y Enfermedades Tropicales (ISET), el cual 
dependía de la Secretaría de Salud, pero su función no era atender pacientes. El plan del Estado era tener un organismo gubernamental que desarrollara investigación científica en medicina; no obstante, la falta de planeación en el sector salud asistencial provocó que los médicos que laboraban en el ISET no pudieran dedicarse sólo a la investigación y su productividad fuera escasa [Pérez, s/f].

\section{EL ESTADO EN LA ORGANIZACIÓN DEL QUEHACER CIENTÍFICO}

Las diferencias entre los académicos e investigadores y el gobierno pusieron de manifiesto la necesidad de coordinar ideas entre ambos grupos. Los años posteriores al cardenismo sirvieron para disminuir las tensiones entre el Estado y la clase intelectual que se estaba formando, una clase que era crítica, analítica, con un ingreso económico superior al promedio de la población, pero sin un lugar propio en la sociedad.

El gobierno se ocupaba de reducir la pobreza que dejaban los ajustes económicos, de mantenerse al margen de los conflictos bélicos internacionales y de continuar con la nacionalización de industrias. En consecuencia, no había políticas enfocadas a este nuevo grupo, los científicos lo sabían, así que optaron por el camino racional que les encaminara al logro de sus objetivos: organizarse.

Para la década de 1940, el Estado tuvo una participación activa en la vida científica del país, ya sea con propuestas desde el gobierno o apoyando las propuestas surgidas desde la sociedad intelectual que cada vez mejoraba su organización.

Durante su sexenio, Manuel Ávila Camacho (1940-1946) retiró el carácter socialista de la educación que había establecido Cárdenas, pero continúo fomentando la educación superior; fue partícipe de la fundación del Colegio Nacional [ITL: 2013]. Y gestionó la formación de la Comisión Impulsora 
y Coordinadora de la Investigación Científica (CICIC),que era una organización gubernamental orientada a la investigación en el área de las ciencias exactas, biología, química, física y matemáticas.

La necesidad de asociación de las personas del ámbito científico-cultural del país llevó a la creación de El Colegio Nacional en 1943, una organización no gubernamental conformada por un biólogo, un físico, un médico oftalmólogo, un cardiólogo, un arqueólogo, un geólogo, un músico, un filósofo, un educador y, al menos, dos escritores y pintores. Entre los nombres de estos personajes estaban Diego Rivera, Issac Achotaren y Alfonso Caso. Quince caballeros fundadores, que acompañados de otros cinco miembros, formaron la primera generación de El Colegio Nacional. El lema: "Libertad por el saber" reflejaba los principios de fundación de la asociación, promover -mediante conferencias especializadas, gratuitas y públicas- el conocimiento en cada área de la cual contaran con asociados.

La relevancia de esta organización no gubernamental es su existencia hasta el día de hoy y los cambios que ha atravesado en diferentes sexenios. Si bien, El Colegio Nacional no es una dependencia o un proyecto de gobierno, el Estado tiene la facultad de modificar algunos de sus artículos. Las dos modificaciones relevantes que ha tenido han sido el número de mujeres y la internacionalización naturalizada de los participantes. En 1971, Luis Echeverría propuso aumentar a 40 el número de miembros y permitir la inscripción a quienes fuesen mexicanos naturalizados cuando menos diez años antes. Veinticuatro años después, en 1995, Ernesto Zedillo modificó uno de los artículos para permitir la asociación de miembros naturalizados mexicanos sin importar el tiempo. El Colegio Nacional es una observación interesante acerca de la participación de las mujeres en el ámbito científico como resultado de un cambio social ideológico, pues fue hasta 1985 cuando la primera miembro mujer se asocia: 
Beatríz Ramírez de la Fuente, historiadora del arte [El Colegio Nacional, 2007].

Otro punto relevante de este periodo fue la inclusión de México en la Organización de las Naciones Unidas para la Agricultura y la Alimentación (FAO). Esta relación no sólo tuvo impacto en las políticas alimentarias del país, sino que también generó la necesidad de especialistas en silvicultura y agronomía, convirtiendo a la alimentación junto con la salud en los dos principales vínculos entre el Estado y la ciencia.

El sexenio de Miguel Alemán Valdés (1946-1952) estuvo caracterizado por continuar con la estrategia de organización científica; quizá como efecto inercial de su predecesor, resaltan dos cosas en este periodo. Por un lado, la transformación del Instituto Nacional de Investigación Científica (INIC), el cual, aunque con un bajo presupuesto, tuvo por función otorgar becas a investigadores en ciencias de alta precisión [Pérez, s/f]. El INIC es una organización interesante porque además de organizar a la comunidad científica, comenzó a promoverla económicamente; era la base de una estrategia nacional en la materia. Por otro lado, la apertura para realizar coloquios de las diferentes áreas del conocimiento y la libertad de prensa fueron clave para hacer públicos los resultados de las investigaciones, así como compartir ideas.

Para la UNAM, este periodo presidencial significó estabilidad simbólica, puesto que el presidente aprobó la construcción de Ciudad Universitaria, un conjunto arquitectónico que además de servir de recinto para esa institución, sería una muestra de la libertad de expresión cultural.

Si bien, los esfuerzos no se originaron en el espacio políticogubernamental, las legislaciones no restrictivas permitieron a la comunidad científica impulsar el conocimiento académico, mientras el gobierno se ocupaba de la promoción empresarial del país.

Los años posteriores marcaron un periodo de baja actividad del Estado en la comunidad científica, salvo por los permisos 
de construcción de más planteles para el Instituto Politécnico Nacional y modificaciones al INIC.

Adolfo Ruíz Cortines (1952-1958) ocupó su gubernatura para generar una política económica que regresara la estabilidad al país. Asimismo, Adolfo López Mateos (1958-1964) y su gobierno no tuvieron un impacto significativo en la materia. Indirectamente, la política de estabilización repercutió en el espacio científico pues los recursos de todas las Universidades e Institutos dependían del gobierno federal.

En 1959, López Mateos firmó un acta constitutiva de lo que era una organización más civil y científica, la Academia de la Investigación Científica. Ésta buscaba la asociación de quienes eran investigadores activos en el país, sin importar el área. La dinámica al interior de la Academia era la discusión crítica y reflexiva del devenir científico; el objetivo, crear una identidad científica. Ésta es otra de las organizaciones que aún existen, ahora con el nombre de Academia Mexicana de Ciencias (1996). La diferencia sustantiva entre los dos momentos de la Academia ha sido el alcance y los instrumentos utilizados, en la primera etapa, la discusión era entre los miembros y el alcance era la comunidad científica; para la segunda etapa, ampliaron el alcance de impacto hacia la sociedad, utilizando como instrumento programas y evaluaciones académicas [AMC: $\mathrm{s} / \mathrm{f}$ ].

Durante 24 años, los científicos se dedicaron a organizarse legitimándose al exterior, con la complacencia del gobierno; al interior, con la apertura dinámica para la formación de una "masa crítica". Las organizaciones son un constructo social [Crozier y Friedberg, 1977/1990] que deriva de la necesidad de los individuos, racional y biológicamente limitados, de alcanzar sus objetivos particulares. Dado que son limitados, el alcance de sus acciones también lo es, por lo tanto, deciden asociarse con otros para incrementar sus posibilidades de lograr sus fines. Crozier y Friedberg, señalan que al ser un constructo social, organizarse es algo artificial que siempre 
tendrá implícito el conflicto; Simony March [1958/1993] por el contrario, ven a la organización como el resultado de la necesidad de cooperación. Hasta la década de 1960, las organizaciones de científicos parecían ser, en efecto, una construcción social; sin embargo, era derivada de la necesidad de cooperar para generar una identidad colectiva.

\section{LA CIENCIA, UN MERCADO DE ALTA DEMANDA}

Las siguientes dos décadas fueron el resultado de 24 años de una comunidad científica en reflexión -ellos querían un lugar en la sociedad y estaban dispuestos a construirlo- y de las políticas de impulso educativo al nivel básico. Por un lado, estaba la demanda de atención hacia el sector científico que no contaba con las condiciones necesarias para desarrollarse. La infraestructura que hasta el momento se había construido carecía de mantenimiento y equipamiento debido al escaso presupuesto que se asignaba para estos rubros. Por otro lado, estaba la demanda de más espacios académicos descentralizados, puesto que los existentes ya no eran suficientes y el área metropolitana cada vez se poblaba con un mayor número de estudiantes que tras haber concluido su educación básica llegaban en busca de la oportunidad de acceder a la educación superior.

El gobierno de Gustavo Díaz Ordaz (1964-1970) identificó que los esfuerzos de gobiernos anteriores en el ámbito científico no eran vinculantes con los requerimientos del sector productivo. El fomento a la ciencia no había sido parte de un proyecto de Estado, en consecuencia, ordenó al INIC que realizara un estudio respecto del estado de la ciencia y la tecnología en el país [INIC: 1970]. Una preocupación similar tenía el sector científico: las condiciones en las que se desempeñaba la educación no correspondían con los requisitos que demandaba el sector laboral. La diferencia entre el Estado y la comunidad 
científica era la urgencia del cambio. Es difícil decir cuánto tiempo se hubiera tomado el gobierno en atender las demandas de los intelectuales si estos no se hubiesen manifestado públicamente, y si el deleznable evento de 1968 no hubiese ocurrido. Lo que sí sucedió fue la fractura -quizás aún sin sanar- en las relaciones del sector académico y el Estado, debido a la represión política de los grupos de oposición durante la década de 1960 .

Aquel estudio solicitado por Díaz Ordaz derivó en la desaparición del INIC y en la creación del Consejo Nacional de Ciencia y Tecnología (Conacyt), un organismo que el gobierno consideró como instrumento para restablecer el diálogo con la comunidad científica [Pérez, s/f]. En 1970, Luis Echeverría Álvarez formalizó la creación de Conacyt y estableció las funciones que este organismo tendría; la principal: coordinar a todos los actores involucrados en el quehacer científico del país. La demanda de atención al sector científico parecía que estaba siendo atendida. Durante el sexenio de Echeverría (1970-1976) la investigación pública aumentó, en parte, porque se le identificó como un factor indispensable para el desarrollo regional, tras la incorporación de México, en 1975, al Sistema Económico Latinoamericano.

Como ya se mencionó, la comunidad demandaba más espacios académicos, las políticas de promoción educativa eran fructíferas, cada vez más jóvenes tenían la oportunidad de concluir la educación media superior en especial en la zona metropolitana; en consecuencia, los dos principales centros de estudio la UNAM y el IPN presentaban sobredemanda. La solución del gobierno fue abrir una nueva universidad que ofreciera una oferta diferente, complementaria, y en un punto geográfico distinto de las ya existentes, así en 1974, la Universidad Autónoma Metropolitana (UAM) abrió sus puertas a la que sería su primera generación [UAM, 2013]. 
LA TRANSICIÓN DE MÉXICO NACIONAL

AL INTERNACIONAL

Los gobiernos de José López Portillo (1976-1982) y Miguel de la Madrid (1982-1988) fueron una época de transición en la cual México participó activamente en relaciones internacionales. La participación internacional, en especial con países avanzados tecnológica y científicamente, trajo al país la necesidad de desarrollar la economía y comenzó a identificar a los científicos como una herramienta clave para lograrlo. La década de 1980 fue un cambio en el pensamiento del Estado mexicano, pues la ciencia se convirtió en parte de la planeación para el desarrollo del país. Sin embargo, no se consideró la principal fuente de ese desarrollo, para eso estaban los energéticos. Entre esos vínculos internacionales estaban la Cumbre Norte-Sur [González, 1984], para la existencia de diálogo entre los países desarrollados y los subdesarrollados; y la General Agreement on Tariffs and Trade (GATT), que proponía una organización económica mundial tras la Segunda Guerra Mundial.

No obstante, esta época de transición se vio envuelta en crisis económicas que significaron para el país la pérdida de científicos, pues aunque el gobierno los reconocía como necesarios, la internacionalización les ofreció mejores posibilidades económicas. La estrategia de gobierno para combatir la denominada fuga de talentos fue la creación del Sistema Nacional de Investigadores (SNI). Consistía en otorgar estímulos a los investigadores residentes en México a cambio de que éstos demostraran su productividad. La Academia de Investigación Científica (AIC) estaría encargada de dirigir el Sistema y su función sería organizar comisiones de científicos activos que evaluaran el trabajo de otros, con el fin de otorgar los estímulos a quien lo mereciera. El problema fue que la AIC no pudo desempeñar eficientemente su papel, así el SNI quedó a cargo del Conacyt. 
El SNI tiene científicos que lo favorecen y otros que no lo consideran como un instrumento completamente eficiente. Lo cierto es que la fuga de talentos es un problema complejo, donde la decisión es completamente individual, por lo tanto, el SNI, como cualquier instrumento de gobierno, difícilmente podrá erradicarlo en su totalidad [González et al., 2013].

MÉXICO EN EL MUNDO DE LAS ECONOMÍAS DEL CONOCIMIENTO

A finales de la década de 1990, Leydesdorff y Etzkowitz [1996] propusieron un modelo al que denominaron triple hélice, que consistía en explicar la existencia de una interacción estructural y funcional que se da entre la industria, el Estado y la academia para la generación de innovación. Aunque el modelo fue diseñado para explicar que el espacio en el que interactúan las tres hélices es el espacio innovador, el concepto general del modelo puede utilizarse para explicar la construcción ideológica de la ciencia en la sociedad. Leydesdorff señaló que el modelo es un símbolo de la interacción entre los tres sectores, el cual es flexible a la construcción de cada sociedad por medio del discurso y sus instituciones [Leydesdorff, 2005].

Utilizar este modelo para explicar lo que sucedió en los últimos doce años del siglo xx resulta útil y pertinente. Para 1988, la hélice académica se estaba consolidando como indispensable (aunque aún no como protagónico), la industria privada tenía cada vez más cabida y el Estado eligió no hacer una política de innovación. El sexenio de Carlos Salinas de Gortari (1988-1994) fue determinante para la inversión privada, ya que el Estado decidió modernizar las empresas del gobierno privatizándolas. Esto llevó a que las empresas mejoraran sus procesos tecnológicos, pero no tuvo un impacto directo en la contratación de los científicos nacionales [Sebastian, 2007]. Las dos grandes inclusiones de México en el 
mundo globalizado durante el salinismo fueron la firma del Tratado de Libre Comercio de América del Norte (TLCAN) y la incorporación a la Organización para la Cooperación y el Desarrollo Económicos (OCDE) [OCDE, 2009]. Por un lado, el TLCAN era la oportunidad para competir en el mercado internacional. Por el otro, pertenecer a la OCDE era una oportunidad valiosa para fortalecer la administración pública con base en recomendaciones internacionales, las cuales establecían un punto de comparación de México respecto de otros países.

El Estado salinista implementó una estrategia política en materia de ciencia y tecnología que permitió la modernización de este sector, entre las principales acciones estaban la normalización de los procesos productivos, la protección intelectual, la posibilidad de transferencia tecnológica, así como la construcción de infraestructura tecnológica. Además, intentó modificar el sentido de la formación de recursos humanos, transitando los objetivos de los apoyos económicos hacia la participación científica en el sector productivo [Conacyt, 1990]. Las ideas eran, sin duda, interesantes y llamativas, lo que el presidente proponía era un cambio total en el paradigma científico; empero, los propios intelectuales intentaron advertir de las consecuencias económicas que esos cambios implicaban, la respuesta del gobierno fue aplicar su nueva política modernizadora.

El último sexenio del siglo inició con crisis económicas y conflictos ideológicos, el ámbito intelectual también estaba en cambio. El plan de acción gubernamental era resarcir los daños económicos que las acciones previas habían dejado. Así, en 1995, el nuevo Programa de Ciencia y Tecnología planteó propuestas más mesuradas y objetivos menos inalcanzables, los ejes de la política científica fueron la descentralización científica y tecnológica, el intercambio académico internacional y los financiamientos para ciencia y tecnología. Además de estos ejes, la política del presidente en turno, Ernesto Zedillo Ponce de León (1994-2000), tenía una visión de 
coordinación de las diferentes dependencias de gobierno para apoyar la política científica; no obstante, esta visión no derivó en una política de Estado [Conacyt, 1995].

\section{CIENCIA PARA INNOVAR, INNOVAR PARA COMPETIR}

En la década de 1990, México necesitaba ser un país competitivo a nivel internacional, con productos que pudieran tener cabida en los nuevos mercados globalizados a los que se estaba introduciendo; la mejor manera de hacerlo era ofertando precios menores a los que ya había. Para lo cual requería generar menores gastos, así que en la década de los noventa, México optó por la reducción de costos laborales [Ruíz, 2005]. Al mismo tiempo, países que hasta ese punto se encontraban en una situación de competitividad similar, como los países asiáticos, decidieron una alternativa distinta: economías de escala e innovación tecnológica. En la década siguiente los resultados serían claros: la estrategia de los países asiáticos funcionó. Por lo tanto, las políticas de ciencia y tecnología dejaron de ser políticas separadas, para comenzar la búsqueda del gasto privado en investigación científica, desarrollo tecnológico e innovación [Calderón, 2009]. Un cambio total al paradigma del Estado como la principal fuente de financiamiento del quehacer científico, un proceso diferente al del siglo pasado, un proceso en el que aún transitan el gobierno, los científicos y las empresas.

\section{REFLEXIONES FINALES}

La construcción de una sociedad que reconociera al conocimiento sistematizado como una necesidad fue un proceso que tomó, al menos, 78 años. Los eventos que ocurrieron en las décadas de 1960 y 1970 fueron, más allá de lo trágico, una demostración de que la sociedad mexicana comenzaba a 
comprender que tener una educación universitaria y desarrollar investigaciones científicas no eran un lujo, sino un instrumento útil para desarrollar económicamente al país en las áreas que lo necesitaba. Sin embargo, se requirió al menos otros 24, para asimilar que el conocimiento científico podía ser la base del desarrollo tecnológico y que sin una sinergia entre ciencia y tecnología no habría logrado ser un país productivo. Al gobierno le ha tomado más tiempo comprender que no basta con desarrollar capital humano especializado en diferentes áreas de la ciencia, sino que ese capital humano esté especializado en las demandas reales del mercado o sea capaz de desarrollar nuevas demandas.

Para 2009, la cantidad de investigadores en México por cada millón de habitantes era de 384; baja, en comparación con otros países como Argentina (1 091), Corea (5 089) o España (2 932) [Banco Mundial, 2013]. Este panorama refleja la necesidad de seguir preparando expertos científicos que sean capaces de competir en el mundo globalizado, en este sentido, no basta la cantidad de científicos que haya en el país, si estos no cuentan con los recursos materiales necesarios para realizar investigaciones de competencia internacional. El proceso actual propone una interacción más exigente entre el Estado, los científicos y las empresas; por lo tanto, es necesario que los científicos asuman su papel como una hélice que contribuye a determinar el rumbo del país, pues como la teoría organizacional lo explica y los hechos en México lo demuestran, el contexto gubernamental influye en el individuo científico, pero el científico también determina en el Contexto y lo modifica. 
BIBLIOGRAFÍA

Academia Mexicana de Ciencias [2013], http://www.amc. $\mathrm{mx} /$, consultado el 25 de septiembre de 2013.

Adcock, R. y D. Collier [2001], "Measurement validity: a shared standard for qualitative and quantitative research", en American Political Science Review, vol. 95, núm. 3, Universidad de California.

Arellano, D. [2012], "El enfoque organizacional en la política y la gestión públicas", en Problemas, decisiones y soluciones, Merino et al. México, Fondo de Cultura Económica.

Banco Mundial [2013], Indicadores de desarrollo mundial, consultado el 23 de septiembre de 2013, http://datos.bancomundial.org/indicador/

Bungue, M. [2005/1976], La ciencia, su método y su filosofía, Buenos Aires, Ediciones Sudamericanas.

Calderón, Á. [2009], Evaluación del Programa de Estímulos Fiscales al Gasto en Investigación y Desarrollo de Tecnología de las Empresas Privadas en México (EFIDT), México, Colegio de México.

Cochran, C. [2010/1974], "Political Science and The Public Interest”, en Journal of Politics, vol. 36, núm. 2, Cambridge University Press.

Conacyt [1990], Programa Nacional de Ciencia y Modernización Tecnológica, México, Conacyt.

Conacyt [1995], Programa Nacional de Ciencia y Tecnología, Conacyt, México.

Crozier, M. y E. Friedberg [1977/1990], El actor y el sistema, Ed. Alianza.

El Colegio Nacional [2007], Miembros del Colegio en orden cronológico. Consultado el 18 de septiembre de 2013, http:// www.colegionacional.org.mx/SACSCMS/XStatic/colegionacional/template/content.aspx? $\mathrm{se}=$ miembroslistado\& $\mathrm{t}=4$ FAO [2009], La FAO en México, más de 60 años de cooperación, México, FAO. 
González, G. J. Schiavon, G. Maldonado, R. Morales y D. Crow [2013], México, las Américas y el Mundo 2012-2013, México, CIDE.

González, M. [1984], "México ante el diálogo Norte-Sur", en Foro Internacional, vol. 24, núm. 3, enero-marzo, México, Colmex.

Gutiérrez, M. Á. [2009], "El Consejo Nacional de la Educación Superior y la Investigación Científica y la política de educación superior del régimen cardenista, 1935-1940”, en Perfiles Educativos, vol. xxxi, núm. 126, México, IISUE-UnAM. ITL, Instituto Tecnológico de León [2013], Historia. Consultado el 04 de junio de 2013 en http://www.itleon.edu.mx/ index.php?option=com_content $\&$ view $=$ article $\& i d=202 \& I$ temid $=154$ \&lang $=$ es

Instituto Nacional de la Investigación Científica [1970], Política Nacional y Programas de Ciencia y Tecnología, México. Irigoyen, P. [s/f], La creación de la SEP y el proyecto de José Vasconcelos, México, INEHRM.

León, A. [1975], Plutarco Elías Calles, creador de instituciones, México, INAP.

Leydesdorff, L. [2005], "The triple helix model and the study of knowledge-based innovation systems", en International Journal of Contemporary Sociology, vol. 42, núm. 1, pp. 12-27.

Leydesdorff, L. y H. Etzkowitz [1996], "Emergence of a triple helix of university-industry government relations", en Science and Public Policy, vol. 23, núm. 5, pp. 279-286.

Marsiske, R. [s/f], El movimiento estudiantil de 1929 y la autonomía de la Universidad Nacional de México, México, UNAM, consultado el 12 de noviembre de 2013, http://201.161.2.34/servicios/p_anuies/publicaciones/revsup/res044/txt1.htm\#top

OCDE [16 de junio de 2009], 15 años de México como miembro de la OCDE, consultado el 21 de septiembre de 2013 en http://www.oecd.org/centrodemexico/medios/43096510.pdf 
Pérez, R. [s/f], El Estado y la ciencia en México: pasado, presente y futuro, México, UnAM.

Ruíz, C. [2005], "Hacia un cambio en el paradigma de la competitividad: la importancia de las organizaciones empresariales", en Cimolli, M. B. García y C. Garrido, El camino latinoamericano hacia la competitividad, México, UAM-A.

Sebastian, J. [2007], Claves del desarrollo científico y tecnológico de América Latina, Madrid, Siglo XXI.

Simon, H. [1997/1947], Administrative Behavior: a Study of Decision-Making Processes in Administrative Organizations, Nueva York, Free Press.

Simon, H. y J. March [1993/1958], Organizations, Blackwell. Somolinos, G. [2013], Historia de la Ciencia, Universidad Autónoma Metropolitana, consultado el 11 de noviembre de 2013, http://www.uam.mx/sah/pre-pa/indice.html

UAM [2013], http://www.uam.mx/sah/pre-pa/indice.html, consultado el 11 de noviembre de 2013.

UNAM [2009], Acerca de la UNAM, la UNAM en el tiempo, consultado el 23 de septiembre de 2013, http://www.unam.mx/ acercaunam/es/unam_tiempo/unam/1920.html 


\title{
INICIATIVA PRIVADA E INVESTIGACIÓN CIENTÍFICA
}

\author{
Sharon Iliana Nieto González* \\ Emmanuel García Lima*
}

En muchos países el sector privado constituye una de las principales fuerzas motrices de crecimiento económico porque genera empleos e inversión y, en particular, porque es un catalizador fundamental del desarrollo tecnológico y científico [Ibáñez, 2012]. En México no funciona así; la inversión privada en ciencia es mínima y en tecnología es básicamente para importar y no para innovar.

Durante la segunda mitad del siglo xIx y principios del xx, México experimentó una de las etapas más controversiales políticas y sociales; sin embargo, ha sido una de las más fructíferas en términos de economía e innovación. El Porfiriato fue uno de los periodos más importantes en la historia del país, ya que no sólo constituye en lo político el control de Porfirio Díaz, sino que a contraluz es el periodo representante del desarrollo y avance económico que introdujo a México en el sistema capitalista, dando paso a la industrialización, meta perseguida desde los gobiernos previos [San Juan, 1992].

El gobierno porfirista buscó atraer el capital extranjero mediante la inversión de empresarios de Estados Unidos, Francia, Inglaterra y Alemania, sobre todo en áreas estratégicas para la nación como lo eran la infraestructura ferroviaria y marítima, minería, comunicaciones, la industria de la transformación, el petróleo y la electricidad.

El rápido crecimiento económico que la paz porfirista, acompañada de inversión, generó a finales del siglo XIX requirió la profesionalización de la labor científica, por lo que científicos de distintas partes del mundo llegaron al país

*Ambos son egresados de la carrera de Relaciones internacionales de la Facultad de Ciencias Políticas y Sociales, unAm. Becarios del proyecto PAPIIT IN302410. 
para realizar investigación con la cooperación casi siempre subordinada de investigadores nacionales. Como resultado, y gracias a la política de fomento a la ciencia de Porfirio Díaz, México llegó a contar con una impresionante infraestructura científica encabezada por los primeros institutos de investigación que despertaron el interés y reconocimiento internacional, tales como: la Comisión Geodésica Mexicana (1899 con participación de Estados Unidos y Canadá), el Instituto Bibliográfico Mexicano (1899 propuesto para participar en la Royal Society de Londres), el Instituto Antirrábico (1888 bajó el modelo del Instituto Luis Pasteur de París), el Instituto Bacteriológico Nacional (1895) y el Museo AnatomoPatológico (1896), entre otras [Azuela, 2012].

En resumen, el régimen porfirista dejó como legado una sólida infraestructura institucional que sobrevivió a los avatares de las crisis revolucionarias. De hecho, el gobierno de Díaz es precedente a la realidad que imperaría en el país durante todo el siglo xx: la mayor inversión en investigación y desarrollo tradicionalmente proviene del sector público y no de la iniciativa privada.

Durante el siglo anterior, el Estado mexicano realizó a lo largo de varias décadas una importante inversión en ciencia e investigación, muestra de ello son las fundaciones del Instituto Politécnico Nacional, el Consejo Nacional de Ciencia y Tecnología, el Instituto Biotécnico (ahora denominado Instituto de Investigaciones Forestales, Agrícolas y Pecuarias, INIFAP), el Instituto de Salubridad y Enfermedades Tropicales, además de la construcción de Ciudad Universitaria, entre otros ejemplos.

La creación de todos estos organismos ha ocasionado que el Estado sostenga la gran mayoría de la investigación en el país, mientras que la iniciativa privada dedica pocos esfuerzos a esta fundamental tarea [Sánchez, 2012].

Actualmente, las políticas públicas buscan -al menos en papel- establecer vinculación con el sector productivo, esto 
es, que cada vez más proyectos de investigación y programas académicos se orienten a resolver problemas concretos del sector privado y que éste, a su vez, incremente su gasto en ciencia y tecnología.

El Foro Consultivo de Ciencia y Tecnología (ғссут), fundado en 2002, al ser un órgano autónomo y permanente de consulta del Poder Ejecutivo Federal, del Consejo General de Investigación Científica y Desarrollo Tecnológico, y de la Junta de Gobierno de Conacyt y parte del Consejo General de Investigación Científica y Desarrollo Tecnológico, está encargado de regular los apoyos que el gobierno federal aporta para impulsar, fortalecer y desarrollar la investigación científica y tecnológica en el país. El Fссут lleva al Consejo General de Investigación Científica y Desarrollo Tecnológico la expresión de las comunidades científica, académica, tecnológica y del sector productivo, para la formulación de propuestas en materia de políticas y programas de investigación científica y tecnológica. Aunque no ha tenido mucho éxito.

En el Conacyt se plantea el apoyo del sector empresarial por medio del Programa Especial de Ciencia y Tecnología (РЕсут) que tiene por objetivos

fomentar las ventajas competitivas de cada región o entidad federativa con base en la formación de recursos humanos altamente calificados, promover la investigación científica en instituciones de educación superior y centros de investigación, e impulsar el desarrollo tecnológico y la innovación en las empresas situando en su visión empresarial la idea de que el conocimiento científico y tecnológico constituyen una gran fuente de riqueza económica por medio de su adquisición, rápida asimilación, adaptación y generación de nuevo conocimiento e innovación.

Sin embargo, tanto, Conacyt como el FCcyT tienen la misión de vincular, expresar, comunicar y entablar un diálogo entre los usuarios del Sistema de Ciencia, Tecnología e Inno- 
vación (SCTI), los integrantes del Sistema Nacional de Investigadores (SNI), los legisladores, las autoridades federales y estatales, y los empresarios privados, con el propósito de estrechar lazos de colaboración entre los distintos actores. Así como fungir como intermediario entre los proyectos viables de investigación y su posible financiamiento e inversión.

Algunos de los principales programas que buscan incentivar e impulsar la participación de la iniciativa privada son:

Avance. Es un programa creado para impulsar la identificación de oportunidades y creación de negocios basados en la explotación de desarrollos científicos y tecnológicos.

Escuela de negocios Avance. Es un subprograma de Avance que busca promover la participación de empresas e instituciones en el desarrollo y utilización de programas académicos y de extensión, enfocados en el manejo y el uso del factor tecnológico para fortalecer la cultura empresarial de aprecio por el desarrollo tecnológico en México, fomentar la incorporación y difusión de mejores prácticas directivas para el manejo y utilización del componente tecnológico y de conocimiento dentro de las estrategias de crecimiento de las empresas, y apoyar la formación de competencias técnicas en innovación y administración de proyectos de desarrollo tecnológico.

Nuevos negocios. En un subprograma de Avance que fomenta que desarrollos científicos y/o tecnológicos probados en escala piloto o en etapa precomercial puedan convertirse en negocios de alto valor agregado o nuevas líneas de negocio. Paquetes tecnológicos. Es una modalidad de apoyo del programa Avance centrado en la integración del conjunto de elementos (paquete) necesarios para que desarrollos científicos y/o tecnológicos probados y validados en el laboratorio o planta piloto, puedan ser licenciados, comercializados o transferidos mediante una estrategia comercial, legal y tecnológica que facilite su explotación comercial y/o asimi- 
lación hacia el sector o sectores usuarios.

Fondo emprendedores Conacyt-Nafin. Es una modalidad de apoyo que facilita recursos y permite acceder a capital con otros inversionistas, para desarrollar y consolidar negocios de alto valor agregado.

Fondo de garantías. Es una modalidad de apoyo que facilita la obtención y el otorgamiento de crédito a empresas nacionales. El Conacyt opera este programa en colaboración con Nacional Financiera y Banco del Bajío.

Apoyo a patentes nacionales. Es una modalidad de apoyo del subprograma Avance creado para dar apoyo económico a rembolso para la protección de invenciones mexicanas que sean susceptibles de serlo como estrategia para el establecimiento de ventajas competitivas nacionales e internacionales. Aunque la realidad es que el proceso de obtención de una patente es demasiado burocrático y en los hechos no se garantiza una adecuada protección de lo patentado.

Oficinas de Transferencia de Tecnología (отт). Es una modalidad del subprograma Avance centrado en promover la formación y adquisición de metodologías que permitan la consolidación de grupos, centros u отT que fomenten la integración, licenciamiento y/o comercialización de paquetes tecnológicos, la generación y lanzamiento de nuevos negocios y/o el licenciamiento de desarrollos o tecnologías propios.

Alianza Estratégica y Redes de Innovación para la Competitividad (AERIS). Es un instrumento que tiene la finalidad de promover la articulación entre instituciones de investigación y empresas que al utilizar su sinergia incrementen la competitividad del sector productivo que les compete.

Incorporación de científicos y tecnólogos mexicanos en el sector social y productivo del país (IDEA). Es un instrumento de apoyo para mejorar la capacidad tecnológica de las empresas mediante la presentación de un proyecto de innovación y desarrollo (ID), motivo que origina la incorpo- 
ración de un profesionista con maestría o doctorado. Fondo de Cooperación Internacional en Ciencia y Tecnología. Unión Europea-México (Foncicyt). Estimula el fomento de la investigación científica y tecnológica entre México y la Unión Europea para apoyar proyectos de investigación conjunta; así como la creación y fortalecimiento de redes de investigación.

En cuanto al sector privado, también existen esfuerzos destinados a impulsar la participación de las empresas e industrias en la investigación y desarrollo científico y tecnológico, una muestra de ellos son la Asociación Mexicana de Directivos de la Investigación Aplicada y Desarrollo Tecnológico, y el portal Innoversia.

La ADIAT, fundada en 1989, tiene como objetivo coadyuvar con los centros de investigación y desarrollo en el país, públicos y privados, impulsando la investigación aplicada, el desarrollo tecnológico y difundiendo las mejores prácticas de gestión de la tecnología.

En sus inicios, la ADIAT analizó métodos y técnicas de vanguardia concentrados en la investigación y el desarrollo; posteriormente se orientó a la detección de las mejores prácticas para potencializar los procesos tecnológicos en las empresas nacionales. Actualmente, con la experiencia acumulada, la ADIAT cuenta con una perspectiva hacia la innovación, lo cual le permite crear modelos y construir marcos referenciales para contribuir al fortalecimiento de Sistemas de Innovación Regional y de un Sistema de Innovación Nacional.

Innoversia, es un portal que permite conectar las necesidades científico-técnicas de grandes empresas con investigadores, así como consultar las demandas de investigación, según áreas de interés y postular en aquellas necesidades que coincidan con sus líneas de especialidad. Este portal ofrece una plataforma que permite desplegar las necesidades tecnológicas de un gran número de empresas en un único sitio web, 
disponible para todos los innovadores interesados.

En algunas instituciones de educación privadas hay logros modestos en el área de investigación científica y desarrollo tecnológico. Particularmente son los casos de Instituto Tecnológico y de Estudios Superiores de Monterrey (ITESM) y la Universidad de las Américas de Puebla (UDLAP) que aportaron $2 \%$ del total de patentes solicitadas por México durante 2011 [ANUIES, 2012]. Si bien esta cifra puede parecer no significativa, en realidad es un gran avance ya que, tal como se mencionó antes, en México la investigación científica tradicionalmente se ha desarrollado en instituciones públicas.

Según el informe de actividades 2012 del Instituto Mexicano de la Propiedad Intelectual (IMPI), de los cinco principales titulares nacionales de patentes en el país, tres son instituciones públicas y sólo una es empresa comercial.

Cuadro 1. Principales titulares de patentes de origen nacional en México

\begin{tabular}{lcc}
\hline \multicolumn{1}{c}{ Titular } & \multicolumn{2}{c}{ Patentes } \\
& 2010 & 2012 \\
\hline Grupo Petrotemex, S.A. de C.V. & ND & 20 \\
Instituto Mexicano del Petróleo & 17 & 17 \\
Universidad Nacional Autónoma de México & 11 & 9 \\
Instituto Tecnológico y de Estudios Superiores de Monterrey & 7 & 8 \\
Instituto de Investigaciones Eléctricas & ND & 6 \\
Instituto Politécnico Nacional & 6 & 6 \\
Centro de Investigación y de Estudios Avanzados del IPN & 6 & 5 \\
Universidad Autónoma Metropolitana & 7 & $\mathrm{ND}$ \\
Total & 54 & 71 \\
\hline
\end{tabular}

Fuente: Elaboración propia con datos de los Informes de Actividades del IMPI 2010 y 2012.

En contraste, la empresa extranjera en el país tiene una participación abismalmente superior, tan solo la estadouni- 
dense OMM Inc registró 236 patentes en el país durante 2012.

Cuadro 2. Principales titulares de patentes de origen extranjero en México

\begin{tabular}{|c|c|c|}
\hline & Titular & $\begin{array}{c}\text { Patentes } \\
2012 \\
\end{array}$ \\
\hline \multirow{5}{*}{ 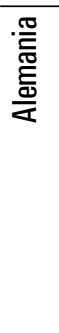 } & BASF SE & 68 \\
\hline & Bayer Cropscience AG & 50 \\
\hline & $\begin{array}{l}\text { Fraunhofer-Gesellschaft zur Förderung der } \\
\text { Angewandten Forschung E.v. }\end{array}$ & 47 \\
\hline & Boehringer Ingelheim International GмBн & 36 \\
\hline & KHS GMBH & 30 \\
\hline \multirow{5}{*}{ 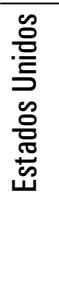 } & Omm Inc. & 236 \\
\hline & Procter \& Gamble Co. & 212 \\
\hline & Kimberly-Clark Worldwide, Inc. & 126 \\
\hline & Microsoft Corporation & 73 \\
\hline & AMGEN Inc. & 69 \\
\hline \multirow{5}{*}{ 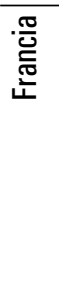 } & Son Licensing & 49 \\
\hline & Sanofi-Aventis & 47 \\
\hline & Sidel Participations & 40 \\
\hline & Saint-Gobain Glass France & 28 \\
\hline & L'oreal & 12 \\
\hline \multirow{5}{*}{ 哭 } & Onic Co. & 70 \\
\hline & NTT Docomo, Inc. & 67 \\
\hline & Sharp Kabushiki Kaisha & 49 \\
\hline & Sumitomo Metal Industries, Ltd. & 31 \\
\hline & Nippon Steel Co. & 29 \\
\hline
\end{tabular}

Fuente: Elaboración propia con datos del Informe de Actividades del impi 2012. 
Según Díaz Rodríguez [2012], algunas de las empresas mexicanas que demuestran tener procesos innovadores, que impulsan el talento humano e incentivan la investigación y el desarrollo tecnológico son: Helvex (desarrolladora de productos de baño), Compañía Mexicana de Radiología CGR, Laboratorios ABC Química Investigación y Análisis, Coprobamex (comercializadora de azúcar líquida) y Steel \& Trucks (fabricante de autopartes).

Los esfuerzos de la iniciativa privada son aún muy escasos, pero hay casos de éxito que auguran un futuro promisorio si es que se difunde correctamente la idea entre la clase empresarial de que la generación, investigación y concreción de los proyectos de ciencia e innovación en el país formulan la pieza clave en el desarrollo de la industria y la empresa mexicana. Es importante que los grupos empresariales participen en el desarrollo del país.

\section{BIBLIOGRAFÍA}

ANUIES [2012], Anuario estadístico 2011, Asociación Nacional de Universidades e Instituciones de Educación Superior, ANUies, México.

Azuela, L. [2012], La institucionalización de las ciencias en México durante el Porfiriato, en línea, tecyc.cepe.unam.mx/ historia/talancon/inst.html, consultado el 20 de junio de 2012.

Díaz Rodriguez, V. [2012], La ciencia de hacer negocios, (en línea), CNN, http://www.cnnexpansion.com/expansion/ 2011/ 12/12/la-ciencia-de-hacer-negocios, consultado el 20 de junio de 2012.

Ibáñez, A. [2012], La innovación, la ciencia y la tecnología, factores para resolver los problemas del pais, en línea, BUAP, http://www.buap.mx/, consultado el 20 de junio de 2012. 
San Juan Victoria, C. [1992], El Estado y las políticas económicas en el Porfiriato, en Ciro Cardoso (coord.), México, Nueva Imagen.

Sánchez, O. [2012], "Urgen al sector privado invertir en ciencia y tecnología” en línea, El Economista, http://eleconomista.com.mx/tecnociencia/2011/12/08/urgen-sector-privado-invertir-ciencia-tecnologia, consultado el 20 de junio de 2012.

Dirección General de Evaluación Institucional [2012], Estudio Comparativo de Universidades Mexicanas ENCUM 2012, UNAM. 


\section{ANÁLISIS DE LAS ENTREVISTAS}

El presente capítulo se basa en las opiniones de prominentes científicos y altos funcionarios de la ciencia en México. Estas opiniones son comparadas con la información oficial y estadísticas disponibles, con la finalidad de obtener una "fotografía" lo más cercana a la realidad del estado actual de la ciencia en el país.

Las entrevistas fueron a profundidad y se les brindó absoluta libertad a los entrevistados para que expresaran su opinión, por ese motivo su identidad se ha mantenido reservada.

Las respuestas de los entrevistados fueron cuantificadas, comparadas y agrupadas en cinco variables mediante el programa N-VIVO ${ }^{\circledR}$. Posteriormente se buscaron coincidencias y divergencias según un análisis por áreas del conocimiento definidas por la UNAM:

Área I. Física, Matemáticas, Ciencias de la Tierra e Ingenierías.

Área II. Ciencias Biológicas y de la Salud.

Área III. Ciencias Sociales.

Área Iv. Humanidades y Artes.

Finalmente, se compararon las opiniones recabadas con datos provenientes de instancias públicas. Cabe señalar que las fuentes oficiales analizan la situación de la ciencia y la tecnología en México de acuerdo con una perspectiva de 
gobierno, que no coincide necesariamente con la perspectiva de los entrevistados.

Con la finalidad de agilizar la lectura, el capítulo se dividió en cuatro apartados: Evaluación y financiamiento; Innovación; Vinculación y colaboración; y Difusión y divulgación. 


\section{EVALUACIÓN Y FINANCIAMIENTO}

\section{Heriberta Castaños Rodríguez*}

Evaluar el trabajo de los investigadores es fundamental ya que permite tener criterios objetivos -en la medida de lo posiblepara asignar justamente los siempre limitados presupuestos, estímulos, equipos, instrumental y otros recursos. No obstante, calificar el desempeño laboral de un científico es difícil ya que no existen indicadores claros que permitan decidir si un investigador es o no productivo. La experiencia en América Latina demuestra que incluso no hay consenso entre los propios científicos sobre cómo deben ser evaluados, de hecho, los países miden su producción científica de diferentes maneras.

En México los mecanismos de evaluación se han generalizado a partir de su desarrollo ligado al ámbito de la investigación y ahora ocupan casi la totalidad de la vida académica y científica. Fue con la creación del Sistema Nacional de Investigadores (SNI), en 1984, que se inició la implementación del sistema merit pay en el país, que a grandes rasgos consiste en evaluar según parámetros de productividad que se expresan no sólo en una retribución económica favorable para quienes son positivamente evaluados, sino también en "prestigio académico" para el investigador.

Hay que recordar que el sNI surge en el contexto de la crisis económica de los ochenta, en la que los salarios sufrieron un

* Investigadora Titular, Instituto de Investigaciones Económicas, Universidad Nacional Autónoma de México. Coordinadora del Proyecto PAPIIT IN302410. 
gran deterioro y muchos de los mejores talentos del país buscaron mejores oportunidades en el extranjero, particularmente en los países más desarrollados. Fue una diáspora que amenazaba con acabar con la comunidad científica nacional. Ante la situación, un grupo de connotados científicos nacionales se acercó al gobierno federal para encontrar una solución, si bien en principio ésta debía consistir en homologar y aumentar la percepción salarial de los investigadores, se prefirió crear un sistema de compensación adicional a sus ingresos ordinarios.

El sistema de evaluación opera mediante comités de evaluadores que siguen unas reglas establecidas para saber cuál es la trayectoria del investigador evaluado. Para ello se utiliza el currículo presentado por el investigador. Si se trata de otorgar algún premio se analiza cuidadosamente si el investigador lo merece y de la misma manera se procede con todas y cada una de las aportaciones que el postulante presenta. Se le da el premio al mejor candidato y cuando no hay un candidato idóneo el premio puede ser considerado desierto.

Sistemas similares de aumento diferenciado en los ingresos fueron paulatinamente reproducidos en las universidades e instituciones de las entidades de la República, mediante una red de comités para la admisión y promoción de su personal académico y científico.

Según los críticos, en un sistema por puntos, el investigador que carece de originalidad es el que más se beneficia porque sólo se reconocen parámetros medibles. Así, siempre gana el que sigue la línea trazada previamente por los evaluadores. En el medio, algunos le llaman a manera de broma el "efecto de Mateo", en referencia al Nuevo Testamento, libro de Mateo, versículo 11-13 que dice: "al que más tiene, más se le dará, y al que menos tiene, se le quitará para dárselo al que más tiene".

Por su cuenta, en la mayoría de estos sistemas "locales" o estatales se adicionó la revisión por pares (peer review), que 
muchos consideran como la mejor forma de juzgar justamente la trascendencia de un trabajo académico, la evaluación del desempeño de otras funciones como la docencia, la dirección de tesis o la divulgación.

Yo puedo entender que a medida que la ciencia crece, hay más personas que están compitiendo por recursos y se vuelve necesario introducir ciertos mecanismos de evaluación. Pero no me parece que lo correcto sea sólo contar y sumar: tantos artículos, tantas tesis, tanto lo que sea, sin fijarse en la calidad de lo que se suma.

Claro, también comprendo que los evaluadores no tienen tiempo ni la suficiente especialización para apreciar cada uno de los muchos trabajos. Entiendo que ante tanto por revisar, tantas solicitudes o propuestas no hay otra forma que contar, pero sigo pensando que no es la mejor manera, debemos encontrar otro modo distinto de hacerlo (investigador del área II).

En principio, muchos investigadores aprueban teóricamente el procedimiento de evaluación por pares, pero en la práctica les resulta oneroso: los entrevistados tienen la obligación de someterse a una evaluación cada tres años con el objetivo de eliminar a los investigadores que han bajado en productividad y debido al crecimiento de la comunidad científica; de ahí que la carga de trabajo de los comités de pares se incremente año con año. De hecho, actualmente suele delegarse la labor de evaluación a un subcomité de dos miembros, modalidad que facilita el trabajo pero que diluye la responsabilidad de los comités y puede conducir a injusticias cuando ninguno de los dos evaluadores comparte la especialidad o disciplina del científico evaluado.

Los trámites burocráticos excesivos en los sistemas de evaluación son criticados por los entrevistados pues a veces llegan a extremos ridículos, comentaron que hay instituciones en las que la postulación de un científico a una promoción o a un premio se descalifica por el solo hecho de omitir algún 
trámite formal como lo es entregar la fotocopia de un documento al evaluador.

Por otra parte, debido a la gran cantidad de evaluaciones que algunas instituciones tienen que realizar, en ocasiones se opta por realizar un cómputo de artículos publicados, ponencias, libros, clases impartidas, etcétera y a partir de ello realizar un primer filtro de evaluados según la sumatoria de los "productos" de su trabajo. Claramente así se facilita el trabajo de los comités evaluadores, pero se omite evaluar la calidad $\mathrm{y}$ trascendencia del trabajo del investigador.

Hoy en día no puedes trabajar cosas muy profundas porque tienes que sacar artículos y libros. Tienes que sacar artículos para que te cuenten; quieren cierta cantidad de artículos al año en revistas muy especializadas de alto nivel. No está fácil que hagas, según yo, cosas muy profundas. Se evalúa también la calidad, pero es muy duro para los más jóvenes o inexpertos tener gran calidad con tan poco tiempo para sacar un artículo.

Puedes estar una investigación que, caramba, no te salen los resultados o lo que habías pensado no era y tienes que empezar desde el principio... Es difícil andar a las carreras (investigadora del área I).

Según los críticos, considerar tantas funciones lleva a pensar que todas las tareas que realiza un académico -por ejemplo la investigación, docencia o la difusión-son igual de importantes y, en consecuencia, se exige que todos los académicos muestren interés y den altos resultados en todas las áreas, lo que afecta el desempeño laboral de los evaluados ya que tienen que distribuir su tiempo en actividades para las cuales no necesariamente se sienten atraídos. Puede haber grandes investigadores que no tengan vocación para el aula y, a la inversa, muy buenos profesores sin interés por desarrollar investigación.

Lo cierto es que resulta bastante complicado establecer una evaluación del todo objetiva. Si se omite ésta la trascen- 
dencia de los trabajos realizados por los científicos forzosamente se hace mediante la percepción y la subjetividad; la evaluación por pares, por su propia naturaleza, no está exenta de prejuicios e inclusive de desconocimiento.

Según los entrevistados, en algunas ocasiones es difícil saber si el juicio de un dictaminador o evaluador es completamente objetivo o si también influyeron en su decisión elementos personales como envidias o rencillas pasadas, e inclusive factores generacionales. Para ello, en la medida de lo posible las evaluaciones por pares deben ser "ciegas", así el evaluador no sabe de quién es el trabajo que debe calificar y lo hace sólo pensando en su calidad y no en el autor.

Sin embargo, a pesar de todo lo que se pueda criticar tanto al SNI como a los programas de evaluación "locales" o estatales, los entrevistados reconocen la importancia de contar con estos mecanismos.

De tener el SNi a no tenerlo, yo creo que es mejor tenerlo. A mí me ha tocado estar en comisiones de evaluación y diría que gran parte de las críticas no tienen conocimiento de cómo funcionan estas comisiones, existe el mito de que las comisiones se dedican básicamente a contar puntos y esto no es así. Que hay errores, aversiones institucionales y personales, sí, como en cualquiera, pero de eso a no tener nada, a mí me parece que es mejor tener una institución como el sNi (investigador del área III).

Yo creo que los mecanismos de evaluación son buenos porque antes la fama de los investigadores se debía a qué tanto se sabían vender, entonces existían grandes figuras de la ciencia que no habían hecho nada y personas totalmente desconocidas que eran grandes científicos. Pero gracias al sistema de evaluación se puede detectar qué tanto se hace realmente y quiénes son verdaderamente buenos investigadores (investigador del área II).

En resumen, aunque tienen deficiencias, los sistemas de evaluación actuales son necesarios para el desarrollo del que- 
hacer científico. De hecho, pese a todas las críticas que se le puedan hacer, actualmente el SNI beneficia a 18555 investigadores [Conacyt, 2012]; lo que representa un crecimiento de $100 \%$ en la última década y un aumento superior al mil por ciento desde su creación, cuando sólo había 1396 investigadores adscritos. A juzgar por las cifras, pese a lo que se puede suponer, el Sistema Nacional de Investigadores tiene el éxito suficiente para que cada año aumenten los científicos interesados en ingresar y permanecer en él.

Gráfica 1. Miembros del sNı por categoría y nivel (2003-2011)

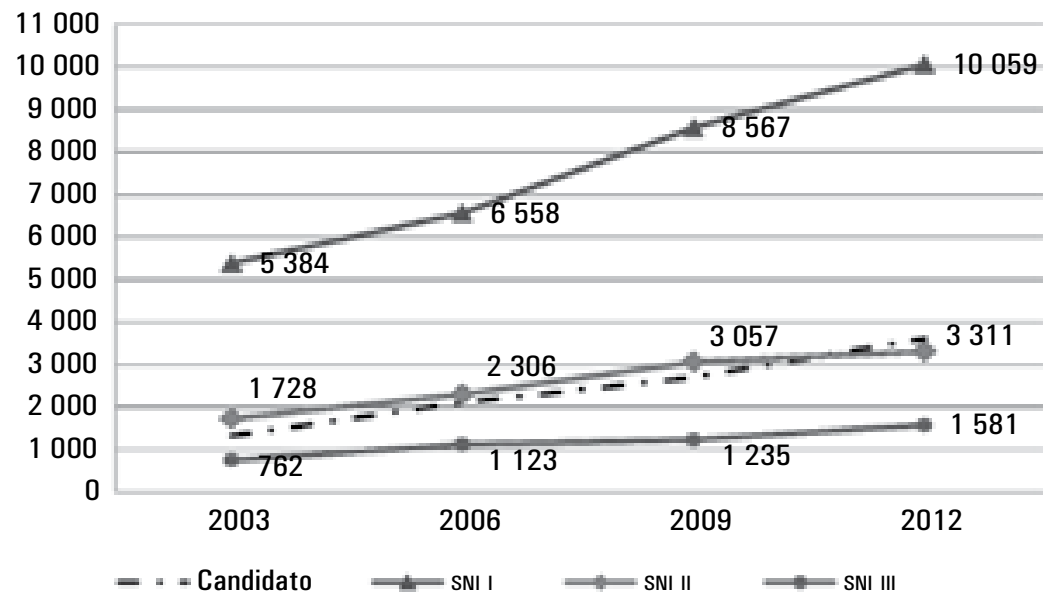

Fuente: Elaboración propia con datos del Informe del Conacyt, 2012.

Otra de las críticas que constantemente se hacen tanto al SNI como al Conacyt es la forma de repartirse los presupuestos. Varios de los entrevistados se quejaron de la lentitud para asignar recursos y la dificultad para obtener las cantidades deseadas, según su opinión, la gestión administrativa para obtener el financiamiento es compleja y lenta.

Uno de los principales problemas actuales de la investigación es que Conacyt se toma mucho tiempo. Es decir, si uno necesita dinero hoy, hay que solicitarlo. Si está abierta la convocatoria, 
¡bien!, pero se abre una vez al año. Si no, se tiene que esperar a que abran la convocatoria. Una vez solicitado el monto, la respuesta se puede tardar hasta un año, lo que quiere decir que ya estuve esperando hasta dos años para comprar equipo que necesito en mi investigación (investigador área II).

A menudo el financiamiento no es un problema, el problema principal en México para este tipo de proyectos son los mecanismos, son cuestiones más humanas, más de tipo administrativo (investigador del área III).

Otra de las molestias recurrentes tiene que ver con la cantidad de dinero disponible para investigación, según la percepción de muchos de nuestros entrevistados, no hay suficientes recursos asignados. Empero, una controversia en medios de comunicación que tuvo lugar a finales de 2012 obliga a reflexionar al respecto. En aquel entonces la Iniciativa de Ley de Ingresos y el Proyecto de Presupuesto de Egresos de la Federación, correspondientes al ejercicio fiscal de 2013 que presentó el Ejecutivo a la Cámara de Diputados, autorizaba la reasignación a otros proyectos de cinco mil millones de pesos que originalmente habían sido destinados al Fondo Sectorial Conacyt-Secretaría de Energía-Hidrocarburos -fondo que tiene la finalidad de promover la investigación aplicada, tanto a la explotación, exploración y refinación de hidrocarburos, como a la producción de petroquímicos básicos-. Ante las críticas, la Secretaría de Hacienda y Crédito Público respondió que aunque estaba destinado a investigación, lo cierto es que el dinero no era utilizado porque no había proyectos. Según las palabras del subsecretario de Ingresos de la Secretaría de Hacienda, Miguel Messmacher, el desvío provenía de un "saldo a noviembre de siete mil millones de pesos" del fondo que "desafortunadamente no ha sido capaz de emplear estos flujos de recursos, entonces está generando una bolsa cada vez más grande de recursos sin utilizar" [Rosas, 2012]. Si en efecto no hay en el país suficiente dinero 
destinado a investigación y desarrollo, ¿cómo puede darse el caso de que no se utilicen recursos tan cuantiosos como siete mil millones de pesos?

Según la opinión de algunos de nuestros entrevistados, ello se debe a la forma en que el presupuesto es repartido y a la presencia o ausencia de proyectos de gran envergadura en el país en áreas específicas del conocimiento.

La cuestión no es el dinero, el dinero está aquí, es una cuestión administrativa, burocrática, de regulaciones, de reglamentaciones, de trámites que pasar (investigador del área III).

El presupuesto Conacyt, cuenta con miles de millones de pesos dedicados a la parte tecnológica y a la ciencia básica. Pero en México no se intenta priorizar, no en el sentido de racionalizar, sino de ver qué proyectos funcionan más para que se les de dinero pero no hay la capacidad para tomar esas decisiones (investigador del área III).

Es cierto que el crecimiento económico de un país y el bienestar de su población están asociados con su capacidad para generar y utilizar conocimiento [Sala i Martin, 2000] y que los países desarrollados aportan entre $1.5 \%$ y $2 \%$ de su producto interno bruto (РIB) al financiamiento de la ciencia y la tecnología, mientras que los países en vías de desarrollo aportan menos de $0.8 \%$, como es el caso de México [Conacyt, 2012]. Definitivamente, en comparación, el país no hace todo lo que debería y podría, pero también es verdad que hay cuantiosas sumas de dinero que no se aprovechan de la mejor manera.

Sin embargo, la cantidad de recursos con la que se trabaja es muy limitada. Un laboratorio como el mío cuenta con menos de cien mil dólares para operar anualmente, sin tomar en cuenta salarios, sólo para gastos operativos. Y un laboratorio en Europa o en Brasil o incluso los laboratorios ricos de Argentina pueden contar con tres a cuatro veces esto y en un laboratorio de Inglaterra o Estados Unidos pueden contar con diez veces esta canti- 
dad. Así que son distancias muy importantes (investigadora del área II).

La individualización se debe a las formas de evaluación, porque política científica nunca ha habido, se da dinero a las universidades, hay una gran cantidad de becas, pero nunca se ha ocupado el gobierno de generar un política de ciencia y tecnología que diga hacia dónde ir y qué desarrollar (investigador del área I).

Se deben encontrar mecanismos que permitan una mejor asignación del presupuesto, basados en priorizar la búsqueda de soluciones para los problemas urgentes y reales del país, mediante procedimientos administrativos que faciliten al investigador hacerse de recursos, y con una perspectiva que incentive la participación de múltiples investigadores que realicen trabajos ambiciosos y de carácter estratégico para la nación.

Se debe fomentar los grupos de investigación. Yo creo que esto debe de surgir desde las instituciones como Conacyt en conjunto con los investigadores. El Consejo tiene poco dinero y la mayoría se le va en dar becas y en mantener su burocracia, así que no tiene con qué resolver este tipo de problemas. Por lo que el marco institucional se debe ampliar, las demás secretarías deben de participar en el fomento a la ciencia. Y, por otro lado, los investigadores deben ser más activos y dejar de pensar en que nos tienen que estimular para trabajar (investigador del área III).

Por otra parte, tal como se mencionó en el segundo apartado, en México predomina el financiamiento público en investigación y desarrollo. En la era del conocimiento, la investigación es una tarea tan importante que no debe dejarse sólo en manos del Estado, todos los actores sociales deberían estar, en mayor o menor medida, involucrados en este pro- 
ceso. En México, la iniciativa privada sólo gasta en investigación y desarrollo 90 centavos de dólar por cada dólar que invierte el Estado, mientras que por ejemplo, en Japón y Corea del Sur, gastan, de manera respectiva, cinco y tres dólares por cada dólar del sector público.

\section{BIBLIOGRAFÍA}

Campos, M. Á. [1992], Política científica e innovación tecnológica en México: retos para la universidad, México, UnAM. Conacyt [2012], Informe General del Estado de la Ciencia y la Tecnología, Edit. Conacyt, México.

García Alba, P. y Serra Puche, J. [1984], "Causas y efectos de la crisis económica en México", Jornadas, núm. 104, México, El Colegio de México.

Rosas, T. [2012], "Preocupa a PRD recorte a fondo de Conacyt" en El Economista, 31 de diciembre, consultado en http:// eleconomista.com.mx/entretenimiento/2012/12/13/reservaran-punto-concerniente-fondo-sectorial-conacyt

Sala i Martin, Xavier [2000], Apuntes de crecimiento económico, Barcelona, Editorial Antoni Bosch. 


\section{INNOVACIÓN}

Viridiana Flores Ochoa*

El estudio de la innovación en la actualidad ha sido el paradigma a la solución de diversas problemáticas. Lo sobresaliente de este concepto es que crea un efecto en la generación de riqueza de las economías. El primero que menciona el concepto de innovación es J. A. Schumpeter en su obra Teoría del Desenvolvimiento Económico. En donde plantea que la innovación es el elemento central que produce el fenómeno del desenvolvimiento económico y la evolución en la historia del sistema capitalista [Schumpeter, 1997].

La innovación consiste en implementar cambios significativos en los productos, procesos u organización de la empresa con el propósito de mejorar los resultados y maximizar las ganancias. Las innovaciones se realizan mediante la aplicación de recientes tecnologías y conocimientos o de nuevas combinaciones de conocimientos y tecnologías existentes, mismos que pueden desarrollarse de manera interna, en colaboración externa o ser adquiridos mediante la importación de tecnología [Schumpeter,1997].

Las naciones desarrolladas han invertido en desarrollo científico y tecnológico desde hace mucho tiempo y, en la mayor parte de ellas, de manera constante y creciente. En estas naciones hay el convencimiento y la evidencia de que

* Egresada de la carrera de Relaciones internacionales de la Facultad de Ciencias Políticas y Sociales,unam. Becaria del Proyecto PAPIIT IN302410. 
el conocimiento científico de frontera transformado en tecnología, resuelve problemas, genera trabajo y satisfactores. En estos países la importancia de la ciencia y la tecnología como palanca del desarrollo no está en duda y es parte de su cultura. En muchos de estos países hay un acuerdo implícito o explícito para fomentar el desarrollo científico y tecnológico, la innovación y la competitividad con base en el conocimiento científico en donde los diferentes actores (gobierno, academia y sector privado), conjugan esfuerzos y definen compromisos para este propósito.

A pesar de la importancia de la innovación, al analizar algunos de sus indicadores en México, se encuentra un panorama de resultados poco alentadores. En cuanto a la actividad inventiva en México se encuentra disminuída, ya que ha pasado de 0.08 en 1990 a 0.04 en 2000 [Conacyt, 2002]. En el bienio de 1999-2000, 28\% del total de las empresas manufactureras [Conacyt, 2002: 16] presentan algún tipo de innovación. "Los sectores más dinámicos al respecto fueron, el de alimentos, bebidas y tabaco con una tasa de $38 \%$ de las empresas; le siguieron la de maquinaria, equipo, instrumentos y equipo de transporte con 37\%; y la de carbón, petróleo, energía nuclear, químicos y productos de caucho y plástico con 36\%" [Conacyt, 2002: 16].

Esta información nos muestra que el proceso de innovación es poco dinámico, ya que solo tres sectores han generado más innovación. Consideramos que esta carencia en innovación es una causa importante del pobre desempeño de la economía mexicana en términos de crecimiento económico.

Lo cierto es que temas de innovación y desarrollo tecnológico son absolutamente novedosos y hay pocas empresas mexicanas que logran ser competitivas y creativas. En general, se considera que parte de la tecnología está vinculada con empresas e instituciones en el extranjero, a las cuales se les compra. En México no hay tecnología que ayude a los investigadores a realizar un trabajo. 
Tal como menciona un investigador del área I:

Siempre ha sido un poco difícil dicha relación, ya que la industria mexicana tiene mucha relación con Estados Unidos y trabaja con patentes. Por ello, acude menos a la ciencia de nuestro país. Es una necesidad importante que la industria se vincule y apoye la investigación nacional. Hay muy poca relación entre la industria y la ciencia y eso siempre ha limitado su desarrollo. Si e logra una mayor vinculación con la industria, se logrará un aprovechamiento práctico en los conocimientos que se están generando.

La innovación dentro de los sectores productivos industriales, debe ser fundamentalmente del país. Eso es derivado del trabajo de investigación, pero debe trascender: se debería generar mucha innovación en las empresas, y también en las universidades, así como en los centros de investigación. Desgraciadamente en México el sector industrial es poco innovador, y el sector productivo, en general, tampoco lo es.

Mientras que a las empresas con espíritu innovador les interesa el talento de jóvenes recién egresados porque son creativos y proporcionan ideas que resultan benéficas para la empresa, la iniciativa privada tipo "maquila", tradicionalmente se limita a reproducir esquemas de producción deficientes que generan ganancias gracias al detrimento salarial de los trabajadores y no por las ventajas competitivas que tales métodos podrían reportar a la empresa.

Los países que realmente han avanzado de manera más contundente en desarrollar ciencia, desarrollar aplicaciones tecnológicas, ser innovadores, y formar cuadros de alto nivel, tienen un mayor desarrollo económico y social, debido a que hay desarrollo tecnológico muchísimo mayor.

La ciencia es innovadora. La ciencia sirve para hacer más ciencia, genera tecnologías para crear satisfactores sociales. La gente piensa que la ciencia sirve para mejorar la situación de la sociedad, entonces innovar sirve para optimizar. La 
innovación realmente responde a comprender el universo en el que vivimos sin darle una connotación comercial.

ÁREA II: CIENCIAS BIOLÓGICAS Y DE LA SALUD

La innovación es intrínseca al quehacer científico de ahí que sea una de las premisas fundamentales del desarrollo científico y tecnológico, opinan los expertos del área II. El objetivo de la ciencia es develar la realidad y esto sólo es posible si se estudia lo que no se conoce, lo inacabado.

Los investigadores expresan que, lamentablemente, México tiene alto nivel de dependencia científica y tecnológica, y bajo en innovación. Todo se trae del exterior. Para algunos, incluso, no hay innovación en México, es inexistente. Más que innovar, lo que se hace es desarrollar las técnicas del extranjero y sólo algunas veces adaptarlas al espacio específico mexicano.

En México se han limitado a reproducir tecnologías que se han desarrollado en el extranjero. Esto por supuesto crea una dependencia y nos hace no ser autosuficientes. Un ejemplo puede ser la crisis de la influenza que vivimos el año pasado; en México dependíamos no sólo de vacunas y posibles medicinas, sino incluso de métodos de detección de la influenza en posibles enfermos. Esto es consecuencia de que no hemos trabajado lo suficiente a nivel de investigación y después ya de desarrollo tecnológico para tener nuestras vacunas y contrarrestar los efectos de dichas epidemias (investigador del Instituto de Investigaciones Biomédicas, UNAM).

ÁREA III: CIENCIAS SOCIALES

Dentro de este rubro se puede destacar la necesidad de generar cuadros de alto nivel que satisfagan la necesidad del 
sector privado, ya que para que el conocimiento científico florezca debe haber una demanda en el mercado laboral. Se recomienda elaborar una planeación de fondo e incrementar la participación del sector privado en cuanto al desarrollo de la misma, como en otros países más desarrollados en este aspecto, lo que no sólo mejorará el desarrollo de la educación y el crecimiento de la producción científica, sino también la productividad, eficiencia y competitividad entre empresas. Esto lleva a un crecimiento económico y a una mejora de la calidad de vida en la población mexicana.

\section{ÁREA IV: HUMANIDADES Y ARTES}

La innovación es un tema que va de la mano del financiamiento. Un país que no tiene una tecnología propia es un país que no tiene los elementos para salir adelante. ¿Cómo se le va hacer si México no desarrolla su propia tecnología?, ¿se seguirá comprando tecnología?, ¿se seguirá generando esa dependencia? Los países que actualmente quieren lograr en poco tiempo una independencia económica contemplan la manera de ser autosuficientes, por ejemplo, en el ámbito alimentario. China, Brasil, India, Rusia y países asiáticos como Corea, lo primero que observan es que si no tienen tecnología siempre serán dependientes. ¿En qué puede ayudar el aumentar la inversión en ciencia y tecnología? Pues en que se sea realmente independiente como país.

Otro punto de encuentro entre la innovación y el financiamiento es el equilibrio que se requiere en el apoyo a las distintas áreas. Aquí la opinión de los investigadores no es unánime, pues aparentemente se requiere un mayor apoyo a las tecnologías para tener desarrollos tecnológicos propios. Quizá el equilibrio consistiría en apoyar la ciencia básica, generar el conocimiento antes de aplicarlo, pues sería un catalizador, porque entre más tecnología se genera hay más 
posibilidades de que el país por sí solo se enfrente a sus problemas y los resuelva. Es ahí donde entra el ingenio y los investigadores de ciencia básica pues ellos mismos afirman que es necesario buscar nuevas formas de hacer las cosas para en realidad generar tecnología innovadora y nuevo conocimiento. Es lo que fundamentalmente significaría el equilibrio que hay que buscar entre la generación del conocimiento y su aplicación, independientemente de las áreas de conocimiento.

No obstante, el Conacyt sí debería priorizar las áreas de conocimiento que se mencionan en el Peciti (Programa Especial de Ciencia Tecnología e Innovación), pues en materia de innovación es necesario también vincularse con la política pública para establecer las metas por alcanzar y las estrategias que deben seguirse de manera general en el Programa de Ciencia y Tecnología que establece la ley. Es necesario definir a los actores involucrados, los apoyos que deben darse, a cuáles sectores deben dirigirse y de qué manera la sociedad se verá beneficiada con ello: cómo puede apropiarse del conocimiento que se genera.

Para cerrar el tema de innovación, se retoma un aspecto que parece muy interesante y más para el área que atañe directamente, que son las humanidades y las artes. Desde la perspectiva de los humanistas y teniendo en cuenta los párrafos anteriores, la innovación no es únicamente generar tecnología. De ser así no cabrían ciencias en las que el producto final son libros o teorías. La innovación también tiene que ver con la manera en que cada investigador trabaja en su disciplina, porque a fin de cuentas también las áreas sociales y de humanidades hacen investigación y son parte del sector productivo. La investigación y el conocimiento también son bienes y se habla del sector productivo como si no fuera parte de él. La realidad, dicen los investigadores en el área humanística y de ciencias sociales, es que "sí lo somos", se producen bienes, que son los conocimientos. Eventualmente también se debe incluir servicios como la docencia. 
BIBLIOGRAFÍA

Castañón Ibarra, Rosario [2005], La política industrial como eje conductor de la competitividad en las pyme, CIDE, Fondo de Cultura Económica, México, D.F.

Conacyt [2002], Informe General del Estado de la Ciencia y Tecnología, Consejo Nacional de Ciencia y Tecnología, México, D.F.

Schumpeter, J. A. [1947], "La dinámica de la competencia y el monopolio", Hunter, Alex, Monopolio y competencia, Madrid, Editorial Tecnos.

Schumpeter, J. A. [1997], Teoría del desenvolvimiento económico, México, Fondo de Cultura Económica. 


\section{VINCULACIÓN Y COLABORACIÓN}

\section{Eduardo Muñiz Trejo*}

La vinculación es el proceso mediante el cual los científicos establecen redes de comunicación y colaboración con distintos actores de la población, quienes pueden ser otros investigadores, empresarios, políticos o la ciudadanía en general. Cada tipo de relación se enmarca en particularidades diversas que van desde la firma de acuerdos institucionales de colaboración, hasta el establecimiento de amistades personales. De la extensión y forma de estas redes depende la magnitud del impacto de la ciencia en el desarrollo nacional.

En general se puede agrupar a las relaciones en dos categorías: las que generan redes internas y las que se vinculan con redes externas a la comunidad científica. Por las primeras se entiende todos los vínculos que los investigadores establecen y mantienen con sus homólogos, mientras que las redes externas se refieren a los intercambios que la comunidad científica tiene con el resto de la sociedad.

* Egresado de la licenciatura en Ciencia Política y Administración Pública. Actualmente se desempeña como asistente de investigación en el Instituto de Investigaciones Económicas, UNAM. 


\section{REDES INTERNAS}

La ciencia siempre es resultado de un trabajo colectivo. Cuando el físico Pedro Miguel Echenique ${ }^{1}$ afirmó que la ciencia es "la obra cultural colectiva más importante de la humanidad", lo hizo en el mismo tenor que cuando Newton se dijo "sentado en los hombros de los gigantes". En efecto, todo descubrimiento científico ha sido posible gracias al trabajo de cientos de investigadores que no necesariamente han coincidido en el tiempo o el espacio, pero que mediante sus conocimientos nutren los pensamientos de otros. Un científico solitario y aislado sólo es posible en la imaginación.

Es ampliamente conocido que el intercambio epistolar que mantuvieron Einstein y Max Born fue de utilidad para que el primero formulase la explicación del efecto fotoeléctrico y por la cual recibió el Premio Nobel de Física. No hay una idea nueva que no esté presidida de otras que la sostengan o que posibiliten su formulación, por lo que la colaboración científica es esencial en la actividad profesional de cualquier investigador.

Además, no sólo es una cuestión de intercambio de ideas, es también una necesidad dada por la complejidad de los problemas contemporáneos, que exige la colaboración de investigadores de diversas ramas del conocimiento y de distintas instituciones. Por ejemplo, la construcción y puesta en marcha del robot Curiosity, y principalmente la interpretación de los datos que ha enviado desde Marte, ha requerido una gran cantidad de expertos en toda clase de conocimientos -desde ingenieros hasta bioquímicos- y la colaboración de diferentes agencias e instituciones de distintos países. La importancia de la colaboración interinstitucional y multidis-

${ }^{1}$ Premio Príncipe de Asturias de Investigación Científica y Técnica. Palabras del discurso que pronunció cuando la Universidad Pública de Navarra le invistió como doctor Honoris Causa. 
ciplinaria para el progreso de la ciencia es irreductible.

Por el resultado obtenido de las entrevistas, se puede afirmar que los científicos mexicanos tienen muy clara la importancia de establecer vínculos de colaboración con otros investigadores, tanto en el ámbito nacional como internacional.

La ciencia es comunicativa y por supuesto que tenemos comunicación con mucha gente, incluso sin comunicación tenemos vínculos. Por ejemplo: yo en este momento aprovecho lo que está haciendo alguien en la India sin siquiera haberlo visto nunca, ésa es la forma de mantenernos al día (investigador del área III).

Hace rato que no he hecho proyectos sólo de mi universidad porque son financieramente limitados, y justamente a nosotros nos interesa hacer un trabajo con un diálogo, no es suficiente sólo hacerlo entre nosotros. Lo que quiero es hacerlo con terceras partes (investigador del área II).

A casi la totalidad de los entrevistados le agrada mucho conocer a otros investigadores en particular mediante la participación en congresos, seminarios y talleres. Si bien les gusta colaborar con otros colegas, no son muy entusiastas del trabajo en grupos numerosos o con demasiada diversidad de especialidades o instituciones involucradas.

En el proyecto multidisciplinario que desarrollamos en Cinvestav interactuamos médicos, fisiólogos, biólogos. Para mí ha sido una experiencia muy interesante porque, en general, ya tiene años esta idea de trabajar de una manera multidisciplinaria, pero en la práctica es muy difícil. Muchas veces la manera de hablar o de pensar en las diferentes disciplinas es distinta, este diálogo químicos-bioquímicos o físicos no es sencillo (investigador adscrito al Cinvestav).

Según sus palabras, a pesar de que grupos grandes regularmente reciben mayor presupuesto y pueden abordar de 
mejor manera el objeto de investigación, también tienen la desventaja de que burocráticamente se vuelve más complicado trabajar debido a que deben lidiar con las administraciones de dos o más instituciones y, debido a la diversidad, en su experiencia han encontrado que existen mayores probabilidades de que haya "roces" o "conflictos" entre los integrantes del equipo. Por ello, en su mayoría, prefieren las investigaciones con pocos involucrados antes que grandes proyectos que incluyan a demasiadas personas.

$\mathrm{Al}$ respecto resulta ilustrativa una anécdota de un investigador de ciencias sociales (área III):

Congeniar las agendas de los demás puede ser muy problemático. Escribir, por ejemplo, el libro de los movimientos [...] no tuvo ningún problema, porque nos encerramos durante cinco semanas en mi casa con dos computadoras. Escribimos el libro muy rápido y trabajando veinticuatro-siete. Pero por lo regular no es así de sencillo. Cuando escribí un trabajo con un colega del Reino Unido la distancia fue un problema por las agendas de cada uno: había épocas donde uno tenía una carga horaria, administrativa o de cursos más grandes que el otro. Hubo siempre desfases, uno avanzaba bien en un momento y el otro no y viceversa, entonces era tedioso [...].

Eso cuando el trabajo sólo es entre dos, según el mismo investigador, cuándo son más personas las cosas pueden salir peor. Continúa su relato:

[...] Peor todavía cuando es un equipo el que está trabajando. Por ejemplo, un proyecto que tuve. Éramos un equipo de nueve personas, algunas fuera de México, más un par de becarios. Mucha discusión se iba en congeniar los estilos y estar de acuerdo en qué se iba a decir. Además, hubo gente que no estaba entregando los resultados de acuerdo con lo que se había pactado, entonces ni la literatura estaba siendo tratada con la sofisticación que se exigía, ni los trabajos estaban escritos con 
la calidad que uno esperaba.

Un investigador del Instituto de Investigaciones Sociales de la UNAM compartió una anécdota similar:

Una vez nos ocurrió que una ayudante se casó y se dedicó más tiempo a preparar su boda -mientras cobraba- y equipar su departamento con el amor de su vida -supongo que seguirán juntos, porque esto nos costó la relación-, que a preparar trabajos. Al final terminé reescribiendo o prácticamente escribiendo las cosas que ella debía hacer. Hay que trabajar con gente confiable.

La respuesta a las dificultades de vinculación corre por dos ejes: brindar la infraestructura tecnológica y financiera necesaria para paliar los problemas de las distancias geográficas; y simplificar la burocracia creando organizaciones estables de trabajo interdisciplinario y cooperativo o, en su defecto, generar acuerdos de colaboración para que los investigadores de distintas instituciones no deban acudir con cada autoridad sino sólo con una.

El entramado institucional puede incentivar o desalentar la colaboración. Si el trabajo de un investigador es evaluado (y pagado) de forma individual y en competencia con sus colegas de la institución, no tendrá motivos para ayudar a sus compañeros. En cambio, si el proceso de valoración considera importante el trabajo en equipo y los logros multidisciplinarios, la cooperación tendrá mejor aceptación entre los científicos. Sin embargo, nada de eso servirá si no existe la necesidad o un motivo real para trabajar cooperativamente:

Cualquier proyecto del CERN se realiza en colaboración internacional. Estas cosas surgen de manera natural. Si tú tienes un proyecto enfrente y sabes que no lo vas a sacar y que necesitas especialistas, estás obligado a buscar a esa gente y entonces haces una red. 
Pero surge de la necesidad. En el país no hace falta formar redes de investigadores, hace falta establecer proyectos que creen esa necesidad, sin que nadie lo diga los científicos deben vincularse entre sí (investigador del área I).

Finalmente, la vinculación interna también tiene la ventaja de permitir la formación de nuevas generaciones de investigadores, porque en ella participan estudiantes de diferentes disciplinas y aprenden a hacer investigación rigurosa, habilidad que no se aprende en las facultades. En palabras de una entrevistada:

Nos enriquecemos de la colaboración con los jóvenes, ellos nos ayudan mucho y nosotros también les ayudamos, en esa medida, ellos comienzan su carrera científica y el resultado es la tesis de licenciatura, por ejemplo. En el laboratorio buscamos factores para que se fogueen con las colaboraciones (investigadora del Cinvestav).

\section{VINCULACIÓN EXTERNA}

La antropóloga Margaret Mead [1957] realizó en diferentes colegios de Estados Unidos uno de los primeros estudios sobre la percepción que los jóvenes tienen sobre la ciencia y, en particular, sobre los científicos. A pesar de la distancia geográfica y temporal del estudio, los resultados de la investigación son válidos para el caso mexicano. Mead pidió a los más de 44 mil participantes que enlistaran los aspectos positivos y negativos de los científicos y las principales respuestas se muestran en el cuadro 1. 
Cuadro 1. Percepción del científico en la población

\begin{tabular}{|c|c|}
\hline Aspectos positivos & Aspectos negativos \\
\hline Muy inteligente y estudioso & Encerrado en su laboratorio y aislado del mundo \\
\hline Gran conocedor de su trabajo & Sin otras ocupaciones ni vida social o familiar \\
\hline Apasionado & $\begin{array}{l}\text { Sus conocimientos son secretos o no están al } \\
\text { alcance de cualquiera }\end{array}$ \\
\hline $\begin{array}{l}\text { Metódico y sistemático (aunque a } \\
\text { veces obsesivo) }\end{array}$ & Obsesivo \\
\hline Altruista y desinteresado & \\
\hline
\end{tabular}

Fuente: Mead y Metraux [1957].

En 1967 el Instituto de Investigaciones Sociales de la UNAM publicó el libro Imagen del científico en México, en el cual expone resultados similares a la investigación de Mead. Posteriormente, la Encuesta sobre Percepción Pública de la Ciencia y la Tecnología en México (Enpecyt), realizada por el Conacyt en 2011 en zonas urbanas a la población en general convalidó los resultados de ambos estudios.

Según Enpecyt, sólo la décima parte de los encuestados estaba bien informada sobre temas científicos, mientras que $54.8 \%$ de la muestra contaba con información muy escasa sobre la materia.

La encuesta arrojó otros datos interesantes que demuestran la falta de noción de lo que es un investigador: $55.67 \%$ de los encuestados se mostró muy de acuerdo o de acuerdo con la idea de que "debido a sus conocimientos, los investigadores científicos tienen un poder que los hace peligrosos", y menos de la mitad consideró que entre los principales problemas del país está el poco desarrollo tecnológico y científico. Cuando se les interrogó sobre la participación gubernamental, 85\% de la muestra se manifestó en favor de que se debe invertir más dinero en investigación científica; y cuando se les preguntó respecto de la iniciativa privada, $89.6 \%$ consideró que los empresarios deben cooperar más con los investigadores. 
Resulta contradictorio que se considere a los científicos como personajes peligrosos y al mismo tiempo también se solicite que la iniciativa pública y privada les ayude a realizar su trabajo. Sin duda, algunos encuestados no responden lo que en realidad piensan, sino lo que suponen que desea escuchar el encuestador, pero también es cierto que la ciudadanía mexicana sí reconoce en alguna medida la importancia del saber científico - ¿cómo no hacerlo en un mundo dominado por la técnica y el conocimiento?-, aunque no conoce ni comprende a los que la hacen posible y continuamente confunde pseudociencia con ciencia.

Cuadro 2. Muestra de algunos de los reactivos de la Enpecyt 2011

Porcentajes de respuesta

¿Qué tan de acuerdo está con las siguientes afirmaciones?

Debido a sus conocimientos, los investigadores científicos tienen un poder que los hace peligrosos

Muy de acuerdo De acuerdo En desacuerdo Muy en desacuerdo
5.54
50.13
34.83
3.44

Los científicos y los empresarios deberían cooperar más entre ellos
Muy de acuerdo
De acuerdo
En desacuerdo
Muy en desacuerdo
11.68
78
4.43
0.34

El gobierno debería invertir más en educación científica
Muy de acuerdo
De acuerdo
En desacuerdo
Muy en desacuerdo

17.29

68.08

8.73

0.91

La investigación científica y tecnológica desempeñan un papel fundamental en el desarrollo industrial
Muy de acuerdo
De acuerdo
En desacuerdo
Muy en desacuerdo
9.54
71.55
7.54
0.4

La investigación científica hace que los productos sean más baratos

\begin{tabular}{cccc} 
Muy de acuerdo & De acuerdo & En desacuerdo & Muy en desacuerdo \\
2.8 & 43.96 & 40.03 & 3.29 \\
\hline
\end{tabular}

Fuente: Elaboración propia con datos de la Enpecyt 2011. 
Según los resultados de la encuesta y la percepción de nuestros entrevistados, los mexicanos piensan la ciencia sólo en términos de nuevas tecnologías y comodidades para la vida cotidiana -principalmente en aparatos electrónicos y nuevos medicamentos-, pero no como un valor cultural que hay que proteger e incentivar.

Son muchas las definiciones que pueden darse de cultura, la mayoría de ellas coinciden en que es todo aquello que no es resultado del instinto natural, que se aprende socialmente y que modela y condiciona tanto el comportamiento humano como la forma de pensar y percibir al mundo [Mosterín, 2009]. Cuando una madre decide llevar a su hijo enfermo ante un médico antes que ante un brujo, es gracias a la influencia que ha tenido la ciencia en la cultura.

El diálogo que la comunidad científica ha establecido con la sociedad mexicana aún es precario. El país necesita que el discurso y conocimiento científico alcancen a toda la ciudadanía para que se deje de percibir a la ciencia sólo como un medio para generar nuevos aparatos tecnológicos, y se le acepte como una herramienta útil para formular juicios, tomar decisiones cotidianas y, mediante la cual, transformar al país.

$\mathrm{Al}$ respecto, además de las conferencias y publicaciones de divulgación (que se abordan en el siguiente capítulo), la comunidad científica nacional realiza esfuerzos para entablar lazos colaborativos con la sociedad civil. Por ejemplo, uno de los entrevistados trabaja con una comunidad de agricultores para establecer procedimientos especializados que les permitan obtener el mayor rendimiento posible de sus cultivos con el menor impacto ambiental.

Sin embargo, son muy pocas las industrias de origen y capital nacionales que realizan investigación científica. Durante 2011 sólo $2 \%$ de las patentes otorgadas en México fueron de origen nacional, y la mayoría de ellas son resultado de la investigación en universidades e instituciones públicas [IMPI, 2012]. 
Aunque hay importantes excepciones, lo cierto es que es muy grave la desvinculación entre la comunidad científica y el sistema productivo. Según esta investigación, la empresa mexicana no desarrolla ni investiga porque prefiere comprar la tecnología extranjera que le brinda resultados inmediatos, antes que esperar obtenerlos de los científicos mexicanos. La mayoría del dinero privado de origen nacional invertido en la comunidad científica es para cubrir becas de estudios que parecen responder a un discurso correctamente político y de mercadotecnia antes que a un sincero deseo de potenciar directamente la ciencia nacional.

Las dinámicas propias de la industria y de la investigación son difíciles de empatar debido a que mientras las primeras siempre son una carrera contra reloj por obtener ganancias, las segundas pueden necesitar de tardados procesos de investigación que no son bien recibidos por los inversionistas mexicanos.

$\mathrm{Al}$ respecto, tres respuestas de los entrevistados resultan reveladoras. Un investigador del área II dijo:

Pretender que la investigación se desarrolla en el mundo de la empresa privada es casi una ilusión [...] Estos dos ámbitos están totalmente desconectados, el sector productivo está interesado en hacer dinero a corto plazo y, generalmente, no le interesa la ciencia. Cuando fui director de un centro de investigación, tratábamos de acercarnos a los industriales y lo único que les interesa es hacer dinero rápido, aunque tengan que comprar tecnología cara en el extranjero.

En consonancia, otra investigadora del área I opinó:

Me parece que lo que siempre ha faltado es una mayor vinculación de la ciencia con la industria. Siempre ha sido un poco difícil ya que la industria tiene mucha relación con Estados Unidos y trabaja con patentes, y por ello acude menos a la ciencia 
nacional. Yo creo que es una necesidad importante que la industria apoye la investigación nacional.

Un investigador del área III fue aún más crítico:

La iniciativa privada tiene la estafeta y no quiere correr. ¿Qué pasa en el sector privado que no desarrolla la ciencia y tecnología? Han tenido enormes ganancias en las últimas décadas y ¿dónde está ese capital? Parecería que la mayoría está en Miami, Nueva York... En esas condiciones no vas a generar un mayor nivel científico. Por ejemplo, en China tienes condiciones similares a las de México, incluyendo la corrupción, pero tienes una élite económica que cree en su país. Aquí no estoy seguro, mi experiencia es que no; no quieren correr.

La vinculación entre la comunidad científica y el sector productivo debería ser una acción concertada entre ambos sistemas, en la que el papel del Estado se caracterice por ser el elemento integrador y facilitador del proceso de vinculación, y no que funja como principal y casi único inversionista en la investigación en el país. No obstante, como ya se dijo, en México hay poco interés por articular estos subsistemas.

A semejanza de la iniciativa privada, la clase política se ha preocupado por hilar un discurso que exalta la importancia de la ciencia pero que no siempre se traduce en acciones concretas. Desde 1970 y 1984, luego de la fundación del Conacyt y del sNI, el Estado mexicano no ha emprendido esfuerzos significativos que tengan como objetivo impactar en la realidad nacional, sino que se ha limitado a medidas que únicamente influyan momentáneamente la percepción del electorado.

La asimilación del conocimiento científico en la élite política no dista mucho de la que tiene $77 \%$ de la población, que considera que los astros pueden influir en su vida [De la Peña, 2005].

Como los encuestados de la Enpecyt, no hay político o funcionario público que niegue la necesidad de desarrollar 
la ciencia en el país, pero al mismo tiempo, durante las últimas tres administraciones, el Foro Consultivo Científico y Tecnológico, órgano que tiene por ley la misión de fungir como organismo asesor autónomo y permanente del Poder Ejecutivo, sólo se ha reunido con el presidente de la República en tres ocasiones.

En los diarios de debates del Congreso no es difícil encontrar apologías al conocimiento científico, pero desde 2004 (fecha en que se reformó el Artículo 9 de la Ley de Ciencia y Tecnología) el Estado tiene la obligación de destinar al menos $1 \%$ del PІв a actividades de investigación científica y desarrollo tecnológico. Aun así ninguna de las tres legislaturas que han sucedido aprobaron un Presupuesto de Egresos de la Federación que contemple ese nivel de inversión.

A simple vista, puede pensarse que no es importante que la población tenga niveles aceptables de conocimiento científico o de entendimiento sobre el quehacer de la ciencia. Es común suponer que mientras se cuente con universidades y centros de investigación a los cuales acudir es suficiente, pero eso no es verdad. Una población alejada de la ciencia es más vulnerable que otra que no lo está.

En 2005 Pemex Exploración y Producción compró, a precios por encima de los 100 mil pesos, varias unidades del detector molecular GT-200, aparato producido por la empresa Global Technical Ltd y comercializado en México por Segtec SA de CV; dispositivo que para esa fecha ya había sido declarado ilegal en algunos países [Toninni, 2011].

Supuestamente el fraudulento aparato era capaz de detectar a distancia cualquier tipo de sustancia -desde drogas hasta cadáveres y explosivos- usando el inexistente principio paracientífico del dia/paramagnetismo, según el cual "todas las sustancias tienen una carga magnética que si es estimulada por un impulso eléctrico, crea una atracción entre la sustancia detectada y la propia unidad GT-200", lo cual es claramente una mentira que desafía el conocimiento físico 
que debe tener el estudiante promedio de educación media superior. Pese a ello, durante el sexenio 2006-2012, diversas dependencias también compraron sus propias unidades GT-200, incluyendo la Secretaría de la Defensa (Sedena), la Procuraduría General de la República (PGR) y la Secretaría de Marina (Semar), las cuales lo utilizaron para revisar automóviles, personas y casas en puestos de control, fronteras y operativos diversos.

Cientos de funcionarios estuvieron involucrados en la compra y utilización de esos aparatos: desde el soldado que operaba el dispositivo hasta los diputados de la Lx Legislatura que presentaron y los que revisaron en enero de 2008 un punto de acuerdo en el cual se exhortaba a la Secretaría de Hacienda y Crédito Público a que destinara recursos para la compra de estos "detectores moleculares" [Gaceta Parlamentaria, 2008]. También estuvieron enterados de la existencia y uso del dispositivo decenas de periodistas de periódicos y medios electrónicos de gran prestigio nacional, que mencionaron y hasta aplaudieron los supuestos logros del GT-200. Miles de ciudadanos fueron revisados en su persona o en su propiedad con este aparato y al parecer ni ellos ni los otros recordaron sus clases de física de bachillerato. Durante años nadie se percató de que el gobierno federal y algunos gobiernos locales arriesgaban la vida e integridad de la ciudadanía jugando a los dados con asuntos de seguridad nacional.

Desde 2009, varios científicos mexicanos habían advertido en los diarios y medios independiente del peligro de utilizar este aparato. En 2010 el gobierno británico alertó al mexicano sobre los peligros de usar el dispositivo, aun así se mantuvo su uso del GT-200 en actividades de seguridad.

En 2011, durante el caso de un ciudadano que fue detenido y acusado de narcotráfico porque la antena del detector lo señaló, la jueza del xIv Distrito en Veracruz, Karla Macías Lovera, solicitó a Arturo Menchaca, presidente de la Academia Mexicana de Ciencias (AMC), que realizara un dictamen 
sobre la eficacia del GT-200 [Castellanos, 2011]. Los resultados fueron los esperados: el detector molecular es un fraude. Ante la innegable evidencia, la jueza liberó al ciudadano.

Posteriormente, como resultado de otro juicio similar, en 2012 la Suprema Corte de Justicia de la Nación solicitó a la AMC un peritaje sobre la eficacia del aparato. Las pruebas se retrasaron debido a que algunas instituciones de seguridad se negaban a colaborar, pero finalmente se realizó un examen de doble ciego que confirmó lo que ya se sabía: el GT-200 es un timo. Ese mismo año el gobierno inglés condenó a 10 años de prisión a Gary Bolton, fabricante del GT-200 [González, 2012].

Luego del fallo de la Corte y del escándalo en los medios, las dependencias federales desecharon paulatinamente sus dispositivos GT-200. La última en hacerlo fue la Sedena que apenas en octubre de 2013 ordenó suspender su uso [Jiménez, 2013].

A la administración federal le tomó ocho años corregir un error que implicó el encarcelamiento injusto de inocentes, un número desconocido de cateos ilegales y violaciones a los derechos humanos [Alcántara, 2013]. Si los cientos de involucrados, aun sin tener una formación académica sólida, hubiesen recurrido desde un principio a los expertos, se habría evitado tal desprestigio.

Como ya se dijo, una población ignorante del saber científico es más vulnerable que otra que no lo está. La historia del GT-200 es una clara muestra de la precariedad del diálogo entre la comunidad científica y la sociedad mexicana. La posibilidad de que en el futuro se repita una situación similar es un llamado urgente para fomentar la cultura científica nacional y vincular a los distintos actores de la sociedad. 
BIBLIOGRAFÍA

Alcántara, L. [2013], "Son ilegales cateos realizados con el detector, advierte CNDH" en El Universal, 18 de julio de 2013, disponible en: http://www.eluniversal.com.mx/nacion-mexico/2013/impreso/son-ilegales-cateos-realizadoscon-el-detector-advierte-cndh-207737.html

Berruecos, María L. [2000], "Las dos caras de la ciencia: Representaciones sociales en el discurso", en Revista Iberoamericana de Discurso y Sociedad, vol. 2, núm. 2, Barcelona, pp. 105-130.

Cámara de Diputados X Legislatura [2008], Diario de Debates, año II, 9 de enero de 2008, sesión núm. 4.

Carrión, L. [2005], "Sólo una vez se han reunido Fox y el Consejo Consultivo de Ciencias" en Milenio, 31 de octubre de 2005.

Castellanos, L. [2011], "La pesadilla de los señalados por 'la ouija del diablo'" en El Universal. 10 de octubre de 2011, disponible en: http://www.eluniversal.com.mx/notas/ 799848.html

Conacyt [2011], Encuesta sobre la percepción pública de la ciencia y la tecnología en México.

Conacyt [2012], Informe general del estado de la ciencia y la tecnología, México, Conacyt.

Cuche, D. [1999], La noción de cultura en las ciencias sociales, Buenos Aires, Nueva Visión.

Dávila, P. [2012], "Los detectores moleculares y la ingenuidad mexicana" en Proceso, 21 de enero de 2012.

De la Peña, J. A. [2005], "La percepción pública de la ciencia en México" en Revista Ciencias, núm. 78, abril-junio 2005.

Gaceta Parlamentaria [2008], Con punto de acuerdo, para exhortar a la Secretaría de Hacienda y Crédito Público a 
destinar recursos a la modernización de los puestos de revisión carreteros prioritarios. Número 2420-I, 9 de enero de 2008 (1609).

González, M. L. [2012], "Corte atrae caso de detector molecular GT-200" en El Universal, 29 de agosto de 2012, disponible en: http://www.eluniversal.com.mx/notas/867188. html

IMPI [2012], Informe anual, Instituto Mexicano de la Propiedad, México.

Jiménez, B. [2013], "Ordena Sedena embodegar falso detector" en El Reforma, 26 de octubre de 2013.

Martínez, N. [2011], "Desdén de Calderón por la ciencia, acusan" en El Universal, 18 de octubre de 2011, disponible en: http://www.eluniversal.com.mx/nacion/189958.html

Mead, M. y R. Metraux [1957], Image of the Scientist Among High School Students, disponible en: http://www.ncbi. nlm.nih.gov/pubmed/17774477

Mosterín, J. [2009], La cultura humana, Madrid, Espasa Calpe, Gedisa Editorial, 358 pp.

Olivares, E. [2012], "Gane quien gane, debe impulsar ciencia y tecnología: Menchaca" en La Jornada, 9 de mayo de 2012, disponible en: http://www.jornada.unam.mx/2012/05/09/ sociedad/038n1soc

Poy Solano, L. [2011], "Frustrante, el presupuesto para ciencia y tecnología, asevera Juan Pedro Laclette" en La Jornada, 26 de noviembre de 2011, disponible en: http:// www.jornada.unam.mx/2011/11/26/sociedad/035n1soc

Toninni, A. [2011], Pemex exploración y producción: sobre el GT200. Consultado el 10 de octubre de 2013 en: http://lonjho.blogspot.mx/2011/07/pemex-exploracion-y-produccionsobre-el.html 


\section{DIFUSIÓN Y DIVULGACIÓN}

\section{Eduardo Muñiz Trejo*}

Como cualquier otra actividad humana, el quehacer científico también se asocia con ideas erróneas que por muy difundidas que sean, no dejan de ser incorrectas y tienen consecuencias contraproducentes para el desarrollo de la ciencia. Una de ellas es la creencia de que para hacer ciencia todos los científicos deben forzosamente seguir una misma serie de rígidos pasos predeterminados (observación, hipótesis, experimentación, comprobación, conclusión y difusión), que han recibido el nombre genérico de método científico. ${ }^{1}$

Si bien el trabajo científico siempre incluye observación y experimentación, la realidad es que no es necesario seguir un orden único e inmutable ${ }^{2}$ aplicado a todo tipo de investigación. Según las circunstancias y los recursos, el científico es libre de decidir si procede de manera inductiva, deductiva, heurística o cualquier otra.

* Egresado de la licenciatura en Ciencia Política y Administración Pública. Actualmente se desempeña como asistente de investigación en el Instituto de Investigaciones Económicas, UNAM.

${ }^{1}$ Se recomienda consultar ¿Existe el método científico?: historia y realidad de Ruy Pérez Tamayo.

${ }^{2}$ En un artículo publicado el 7 de febrero de 2001 en el periódico Humanidades de la Dirección de Humanidades de la UnAM, Martín Bonfil Olvera afirma que lejos de ser como una receta de cocina, el quehacer científico se realiza mediante el uso constante del razonamiento crítico y la argumentación basada en las reglas de la lógica, sin un orden establecido y sin garantía de resultados. 
Hace algunos años, en La lógica de la investigación científica de Karl Popper, se aseguraba que no es suficiente seguir un método inductivo predeterminado para que una investigación pueda ser considerada como "científica", sino que se deben cumplir al menos dos principios que garanticen un trabajo de investigación como científico:

a) Reproducibilidad. Se refiere a que las investigaciones y experimentos deben ser potencialmente repetibles en cualquier parte del mundo y los resultados obtenidos en las réplicas deben ser convincentemente similares a los originales.

b) Refutabilidad. Ninguna de las afirmaciones de la comunidad científica es inmutable, todo está sujeto a ser comprobado o descartado mediante la argumentación basada en evidencias sin importar quién o hace cuánto lo dijo.

Según estas ideas, por mucho que una investigación cumpla con el "método científico", si no satisface tales principios no se le puede calificar como científica. Sin embargo, actualmente muchos de los científicos activos y de los filósofos de la ciencia discrepan de los postulados de Karl Popper, en especial, de la refutabilidad.

Sea en consonancia con el principio de reproducibilidad, o como reconocimiento del carácter social y colectivo de la ciencia, y en cumplimiento de un deber para con el resto de la comunidad científica, los investigadores generalmente llevan una bitácora en la que documentan el curso que ha tomado su investigación. A partir de este documento, los investigadores generan artículos y textos que contienen toda la información relevante y precisa sobre el trabajo que desarrollan para que sus conocimientos estén a disposición de todos los interesados y puedan ser reconocidos, validados o discutidos. Esta acción es conocida como difusión de la ciencia. 
En esta área los científicos mexicanos realizan una labor loable pero claramente aún insuficiente. Según el Informe General de Conacyt [Conacyt, 2012: 67], entre 2006 y 2011 el incremento medio de artículos científicos publicados en México fue de $7.6 \%$; de 7234 artículos publicados en 2006, se pasó a 10449 en 2011. Según esta fuente, el país ocupa el lugar 22 en producción de artículos dentro de los países miembros de la OCDE (véase el cuadro 1). Además, según el registro de publicaciones de la Secretaría de Gobernación, en México hay 113 revistas arbitradas que cubren todas las áreas de la ciencia:

Cuadro 1. Participación en la producción de artículos científicos en el mundo durante $2011(\%)$

\begin{tabular}{rlccll}
\hline Núm. & \multicolumn{1}{c}{ País } & \multicolumn{1}{c}{$\%$} & Núm. & \multicolumn{1}{c}{ País } & $\%$ \\
\hline 1 & Estados Unidos & 28.24 & 14 & Suecia & 1.6 \\
2 & Reino Unido & 7.61 & 15 & Polonia & 1.65 \\
3 & Alemania & 7.34 & 16 & Bélgica & 1.44 \\
4 & Japón & 6.3 & 17 & Israel & 1 \\
5 & Francia & 5.34 & 18 & Austria & 0.96 \\
6 & Canadá & 4.76 & 19 & Dinamarca & 0.93 \\
7 & Italia & 4.41 & 20 & Grecia & 0.97 \\
8 & España & 3.8 & 21 & Finlandia & 0.82 \\
9 & Corea & 3.4 & 22 & México & 0.85 \\
10 & Australia & 3.28 & 23 & Noruega & 0.81 \\
11 & Holanda & 2.54 & 24 & Portugal & 0.77 \\
12 & Turquía & 2 & 25 & República Checa & 0.78 \\
13 & Suiza & 1.87 & & & \\
\hline
\end{tabular}

Fuente: Elaboración propia con datos del Informe Anual del Conacyt 2011 [Conacyt, 2012].

Por supuesto, la difusión no se limita a la producción escrita sino que también se da mediante la participación en 
conferencias y congresos especializados así como en la pertenencia a sociedades científicas.

Por otra parte, ya que el objetivo de la difusión es permitir que otros científicos validen la investigación y la recuperen para las suyas, es de esperarse que se utilice un lenguaje especializado que si bien comunica con precisión el contenido, resulta sólo comprensible para los entendidos en la materia, ${ }^{3}$ por lo que la mayoría de la población no está calificada para poder entender esas publicaciones.

En este sentido, elevar la calidad educativa es un paso importante para reducir la brecha entre investigadores y otros ciudadanos, ya que una buena educación le brinda a la población mayores conocimientos para acercarse al trabajo científico y entenderlo. Por supuesto, no se desea que todos los ciudadanos sean científicos, pero sí que tengan suficientes conocimientos para comprender la información generada por los investigadores.

Es imposible suponer que el público en general tendrá los conocimientos necesarios para comprender los resultados de todas las investigaciones de frontera. De igual forma, tampoco es posible que la mayoría de la ciudadanía considere en su plan de vida una actualización académica constante, por lo que la comunidad científica debe encontrar maneras de comunicar sus avances y descubrimientos de forma tal que sean asequibles al ciudadano común lo cual se conoce como divulgación de la ciencia.

A simple vista, parece clara la diferencia entre divulgación y difusión; sin embargo, en la realidad estos términos son continuamente confundidos tanto por la población no especializada como por algunos miembros de la comunidad científica nacional, en particular entre los investigadores de las áreas III y IV (Ciencias Sociales, Humanidades y Artes).

${ }^{3}$ Es imposible encontrar un ejemplar de Nature o Sciencie en los puestos de periódicos. 
Durante las entrevistas se consultó a 50 investigadores de alto nivel sobre cómo difunden y divulgan sus investigaciones, por las respuestas que dieron diez de los entrevistados, se puede deducir que consideran erróneamente como sinónimos la divulgación y la difusión. Por ejemplo, un investigador contestó: "Mi principal forma de divulgación es la publicación de artículos en las revistas especializadas, pero también en congresos, conferencias y seminarios"; otro más dijo: "Además de papers, yo trato de difundir mi trabajo en radio y en periódicos".

Resulta entonces conveniente definir con mayor claridad la diferencia entre difusión y divulgación:

a) Difusión. Se refiere a la comunicación entre pares, es decir, entre especialistas que comparten ideas, proponen líneas de investigación y buscan contactos benéficos entre múltiples disciplinas.

b) Divulgación. Es una labor multidisciplinaria que tiene por finalidad comunicar el conocimiento científico a la mayor cantidad de personas posible [Sánchez, 2002: 5]. Para ello debe dirigir su discurso a un público muy diverso, por lo que tiene que recrear de forma accesible pero fidedigna el conocimiento científico.

O, bien, expresado en palabras de uno de nuestros entrevistados del Instituto de Física de la UnAM:

La difusión tiene varias vertientes: una es por medio de las publicaciones. Una investigación que no se publica es como si no se hubiera hecho. Entonces el primer punto para difundir la investigación que se realiza es publicarlo, y hacerlo en el sitio donde se obtenga mayor visibilidad, donde pueda ser más leído, donde los pares que están trabajando en otras partes del mundo puedan leer; todo ello a nivel de colegas trabajando en los mismos temas. 
Después viene otro nivel que es enterar a la sociedad de lo que uno está haciendo. Esto es un poco más complejo porque se tiene que tratar de escribir la investigación evitando usar tecnicismos o fórmulas, de manera que un joven o una persona no profesionista pueda entender lo que se está investigando y cuáles son las implicaciones de ello. Esto se puede hacer por medio de periódicos, de revistas no especializadas o inclusive en programas de radio y televisión.

No obstante, conocer la diferencia entre difusión y divulgación no es suficiente. Mientras que todos los científicos son difundidores, no todos saben cómo ser divulgadores, y a la inversa, no todos los divulgadores son científicos aunque sí deben tener conocimientos científicos.

La divulgación es una tarea complicada: el divulgador debe llevar a un público no siempre accesible/dispuesto, una visión recreativa y asequible de la ciencia pero que al mismo tiempo, sea fiel y congruente con el conocimiento [Berruecos, 2000: 116].

La divulgación es fundamental, y eso es algo en lo que estamos avanzando lentamente. Avanzamos lento porque hay muy pocos profesionales de la divulgación; nosotros como investigadores tenemos que divulgar, pero esto debería de hacerlo un profesional. Ya hay algunas revistas o secciones en los periódicos que empiezan a divulgar, lo cual es muy importante porque en la medida en que la sociedad sepa la importancia de la ciencia, en esa medida la va apoyar (investigadora del IPN).

En general, los entrevistados opinan que no tienen problemas para difundir su trabajo. Los autores nacionales tienen la capacidad de abrir espacios en revistas internacionales y son bien recibidos en congresos especializados alrededor del mundo. En cambio, un grupo de entrevistados, especialmente los de las áreas I y II (físico-matemáticas e ingenierías, biológicas y de la salud) señaló que principalmente existen 
dos problemas a enfrentarse para divulgar la ciencia: capacitación y medios.

Un investigador del Instituto de Ciencias Físicas de la UNAM nos dijo: "Nosotros, como investigadores, tenemos que divulgar, pero esto debería de hacerlo un profesional de la comunicación [...]”.

Hacen falta procesos de capacitación orientada a desarrollar las habilidades necesarias para divulgar o "[...] carreras que formen a divulgadores profesionales, por ejemplo, una licenciatura en Comunicación de la ciencia" (entrevistado adscrito a la Coordinación de la Investigación Científica). En general, los entrevistados encontraron problemas para hacer llegar su mensaje sin usar un lenguaje especializado, situación que casi no ocurre en las áreas III y IV.

Por otra parte, un notable investigador del Instituto de Investigaciones Jurídicas de la UNAM lamentó que, según su impresión, las grandes colecciones de la Biblioteca Central de la Universidad se tienen "descuidadas" y señaló que la Biblioteca del Estudiante Universitario, que "era lo mejor del pensamiento del mundo y de México en ediciones baratas y accesibles", ya no se consigue en librerías porque ya no hay nuevas ediciones. También lamentó que "se tienen muchos libros en bodega" por los altos costos y porque no están dirigidos a la población común. El investigador también manifestó su interés en que "pronto la unAM pueda tener un canal abierto de televisión" ya que "su canal va bien, pero está en televisión de paga". En una idea similar, un investigador del Instituto de Investigaciones Filológicas lamentó que, a veces, "la televisión de la UNAM es muy seria y lejana a la población, incluso puede parecer un tanto aburrida"; en la divulgación de la ciencia resulta difícil encontrar el punto medio entre la rigurosidad y la cercanía con el público.

Para el divulgador es complicado encontrar espacios para realizar su labor. Lo más común es que acuda a la institución en la que labora en busca de estos lugares, pero regularmente 
los medios de que disponen las universidades e institutos, apenas pueden abrirse brecha en medio de los grandes medios de comunicación comerciales, que difícilmente dan espacio a divulgadores de la ciencia.

Yo creo que hace falta un medio de comunicación que sea capaz de conectar a la sociedad con los investigadores, pues ambos se ignoran mutuamente. A los investigadores no les interesa comunicarse con la sociedad y la sociedad tiene poco interés en los temas científicos (investigador del Cinvestav).

Pero los problemas no acaban allí, como señala Burgos Ruiz, editora de la revista ¿Cómo ves?, es importante ir más allá de la mera divulgación de los resultados de las investigaciones: también hay que pensar en qué tipo de imagen de la ciencia se quiere dar al público [Venegas, 2013].

Esa labor es importante, porque para que la ciencia reciba el apoyo que se requiere, depende de la impresión que la gente tiene de ella. (Por ejemplo) cuando nosotros mostramos la importancia de la química, el público va a aceptar que para que México alcance un nivel de autosuficiencia se requiere de un mayor presupuesto y apoyo continuo a las ciencias (investigador de Física en la UNAM).

El distanciamiento entre la comunidad científica y la sociedad no sólo tiene como consecuencia que un amplio segmento de la población sea susceptible de ser engañada por pseudocientíficos y charlatanes, así como de sus propios prejuicios, miedos y desconocimiento; sino que también implica una baja en la calidad de vida, un desarrollo económico nacional lento y una falta de interés de la ciudadanía que se traduce en políticas públicas ajenas a las necesidades científicas del país: poco presupuesto, trabas al trabajo científico, etcétera. 
Es fundamental reducir la brecha entre la comunidad científica y la sociedad. Tal como señala un investigador: "no basta llegar a los niños, todos los esfuerzos siempre son hacia los niños y eso está bien, pero es necesario llegar sobre todo a los adultos. Son ellos los que toman decisiones ahora”.

En la medida que se logre concientizar a los ciudadanos, presionarán por tener mejores políticas sobre ciencia; los políticos comprenderán -más allá del beneficio electorallas ventajas de incentivar la cultura científica; y la iniciativa privada recurrirá a la innovación y al desarrollo como vehículo de mejora y crecimiento de sus empresas.

Una sociedad culturizada en ciencia tiene mayores probabilidades de obtener el éxito como nación, que una que no lo está.

Afortunadamente, existen en el país esfuerzos por mejorar las condiciones de divulgación de la ciencia. De varias opciones, destacamos tres.

La Sociedad Mexicana para la Divulgación de las Ciencias y la Técnica (Somedicyt), la Dirección General de Divulgación de la Ciencia (DGDC) de la UnAM y el Centro de Difusión de Ciencia y Tecnología (Cedicyt) del IPN.

Somedicyt se fundó en 1986 y es un esfuerzo por crear "puentes" entre investigadores, docentes, industriales, inversionistas y ciudadanía. Esta asociación tiene la característica de que para ser miembro es necesario tener ya una trayectoria reconocida en el gremio, es decir, no aceptan potenciales divulgadores, sino sólo personas con experiencia en la actividad. De esa manera pretende llevar el conocimiento científico a la mayor cantidad de sectores de la población lo más rápido posible, para lo cual organizan cursos, exposiciones, talleres, programas de radio, publicaciones y ciclos de conferencias dirigidos a distintas edades y niveles académicos.

También existe la Dirección General de Divulgación de la Ciencia (DGDC) de la UNAM, que es una instancia que depende de la Coordinación de Investigación Científica y cuenta con 
la participación del Rector, los coordinadores de investigación científica, de las humanidades y de difusión cultural de la máxima casa de estudios. El objetivo de la dirección es fomentar "activamente la extensión de la cultura científica por medio de la promoción, la organización y la realización de actividades de divulgación de la ciencia”. Para ello tiene tres grandes proyectos permanentes: El Museo de las Ciencias Universum, el Museo de la Luz y la revista ¿Cómo ves?, todos ellos de gran valor.

El IPN mantiene desde hace más de diez años dos importantes esfuerzos para difundir la ciencia, uno es el planetario Luis Enrique Erro y otro es la revista Conversus.

Empero, lamentablemente, a pesar de éstos y otros esfuerzos (como los realizados por la Academia Mexicana de las Ciencias), en México, un país en el que apenas hay un científico por cada 8000 habitantes, la divulgación sigue siendo una tarea solitaria que se realiza desde algunas pequeñas trincheras. Los divulgadores tienen que conformarse con breves entrevistas, columnas dentro de los diarios, esporádicos reportajes y, cada vez más, con sitios web y redes sociales. Es necesario ampliar estos esfuerzos hacia medios de mayor alcance como la televisión, la radio e incluso los libros editados por la Secretaría de Educación Pública, que tradicionalmente se limitan a dar un conocimiento muy básico y sin abordar con seriedad la imagen que se quiere dar del quehacer científico. 
BIBLIOGRAFÍA

Berruecos, M. L. [2000], "Las dos caras de la ciencia: Representaciones sociales en el discurso" en Revista Iberoamericana de Discurso y Sociedad, vol. 2, núm. 2, Barcelona. pp. 105-130.

Bonfil Olivera, M. [2001], “Método científico?” en Humanidades, Dirección de Humanidades, UnAM, México, disponible en http://2culturas.blogspot.mx/2001/02/mtodocientfico.html, consultado el 2 de marzo de 2013.

[2003], "La tensión esencial" en El Muégano Divulgador, núm. 23, Dirección General de Divulgación de la Ciencia, unAm, México.

Cereijido, M. [2009], La ciencia como calamidad, un ensayo sobre el analfabetismo científico y sus efectos, Editorial Gedisa, México.

Conacyt [2012], Informe general del estado de la ciencia y la tecnología 2011, Conacyt, México.

Pérez Tamayo, R. [2002], Acerca de Minerva, México, Fondo de Cultura Económica.

Sánchez, A. M. [2002], "Guía para el divulgador atribulado I: Enseñanza y aprendizaje de la divulgación" en El Muégano Divulgador, núm. 17, Dirección General de Divulgación de la ciencia, México, UnAM.

Tonda, J. (coord.) [2002], Antología de la divulgación de la ciencia en México, Dirección General de Divulgación de la ciencia, México, UNAM.

Venegas, D. [2013], "Seducir al público, una tarea de los divulgadores" disponible en http://gaceta.cicese.mx/ver.php ?topico=breviario\&ejemplar $=115 \& \mathrm{id}=1517$, consultado el 6 de marzo de 2013. 


\section{CONCLUSIONES}

Los científicos son un grupo aparentemente heterogéneo y hermético, pero en realidad tienen orígenes muy diversos y trabajan en condiciones diferentes entre sí. Por medio de la multiplicidad de puntos de vista, los entrevistados en este libro han manifestado la diversidad de su quehacer y la riqueza de pensamiento de la comunidad científica nacional, que inclusive pueden llegar a ser contradictorias.

Desde sus inicios, la labor científica mexicana se ha enfrentado con múltiples diatribas que han mermado su desarrollo. Primero fue la persecución y hostigamiento de las prácticas científicas que desafiaban la "verdad" impuesta desde la metrópoli y, recientemente, el desinterés o la genuina incapacidad gubernamental y social para apoyar la labor científica. Por lo tanto, los investigadores han tenido que encontrar mecanismos para paliar la indiferencia o la falta de recursos.

En buena medida, es gracias al esfuerzo de pioneros como Carlos Sigüenza y Góngora, José Antonio Álzate, Gabino Barreda o Nabor Carrillo y de organizaciones de investigadores que la ciencia ha logrado desarrollarse.

Luego de la fundación del Sistema Nacional de Investigadores (1984), el gobierno mexicano no ha vuelto a realizar acciones contundentes que busquen transformar las formas de hacer ciencia en México. El último esfuerzo importante fue la promulgación de la Ley de Ciencia y Tecnología de 2002, que formalmente trata de estructurar el sistema científico del país y asigna $1 \%$ del PIB a investigación y desarrollo, pero que en la realidad no se cumple a cabalidad. 
Varios de los académicos entrevistados coinciden en señalar que no es necesario crear, como recién se ha dicho en medios, una Secretaría de Ciencia, Tecnología e Innovación, ellos consideran que si la Ley de Ciencia y Tecnología funcionase adecuadamente, bastaría con otorgar al Conacyt los fondos necesarios, para transformar la situación de la ciencia en México. Sin embargo, la realidad se impone a la Ley: por ejemplo, el Consejo General previsto por la misma y que es encabezada por el propio Presidente de la República se ha reunido apenas cuatro veces en 10 años y no ha tomado una sola decisión en materia de asuntos estratégicos o de financiamiento. Ni hablar del continuamente incumplido 1\% del PIB.

Si bien es verdad que actualmente la ciencia cuenta con un sistema mucho más robusto que el que tenía a mediados del siglo pasado, también es cierto que la magnitud de su impacto no es, ni remotamente, lo que el país requiere. No es coincidencia que las naciones que históricamente han invertido mayor cantidad de recursos en investigación y desarrollo (ID) sean también los que cuentan con mejores niveles de desarrollo humano e ingreso per cápita.

La ausencia de políticas públicas de largo alcance llevó a una nociva centralización de la educación y la investigación, que apenas hace unos años se ha revertido lentamente. Hace cuarenta años, $80 \%$ de la investigación se realizaba en el Distrito Federal, actualmente la capital genera casi 50\% de la investigación científica del país. Pero este proceso de descentralización parece obedecer más a una demanda local de educación insatisfecha, que a un mayor avance tecnológico y cultural de las entidades federativas.

Aún más, la centralización de la labor científica también es de actores. La mayoría del dinero destinado a investigación proviene de instituciones públicas ya que la iniciativa privada casi no invierte en desarrollo científico. Según el presente análisis, la empresa mexicana no investiga porque prefiere comprar la tecnología extranjera que le da resultados inmedia- 
tos antes que esperar resultados de los científicos nacionales.

A la ciencia de origen académico se le deben los avances científicos y tecnológicos que ha producido México; no obstante, el sector académico no ha sido capaz de divulgar estos avances con la convicción necesaria. En el país aún prevalecen prácticas premodernas basadas en la superstición y el desconocimiento, hay una profunda desvinculación entre la comunidad científica y el resto de la sociedad. Es necesario establecer redes de encuentro entre científicos, políticos y empresarios.

Los científicos entrevistados parecen coincidir en que la solidez de la ciencia mexicana depende de la formación de científicos, de las capacidades para investigar y del presupuesto asignado.

En México formar a un investigador suele tomar muchos años, debido a que el ingreso a la carrera científica es muy tardío (el tiempo de estudios entre la licenciatura y el doctorado es muy amplio). Si a esto se le suma el hecho de que la población universitaria es de las más bajas del mundo, y que las clases medias y altas prefieren enviar a sus hijos a universidades privadas, esto en la generación de nuevos cuadros se ve mermada. Mientras que Alemania, Estados Unidos o Corea tienen más de ocho investigadores por cada 1000 habitantes, México cuenta sólo con uno y aun así hay logros efectivos que deben ser reconocidos.

La comunidad académica hace un enorme esfuerzo por generar conocimiento, pero resulta necesario que se involucre decididamente en el desarrollo tecnológico y la resolución de problemas prácticos y reales del país. Hay que consolidar la relación entre el sector público, la iniciativa privada y la comunidad científica, ya que si la ciencia no es accesible a la ciudadanía, ésta nunca la valorará ni la considerará como un pilar fundamental de las sociedades contemporáneas. 
ANEXO ESTADÍSTICO 


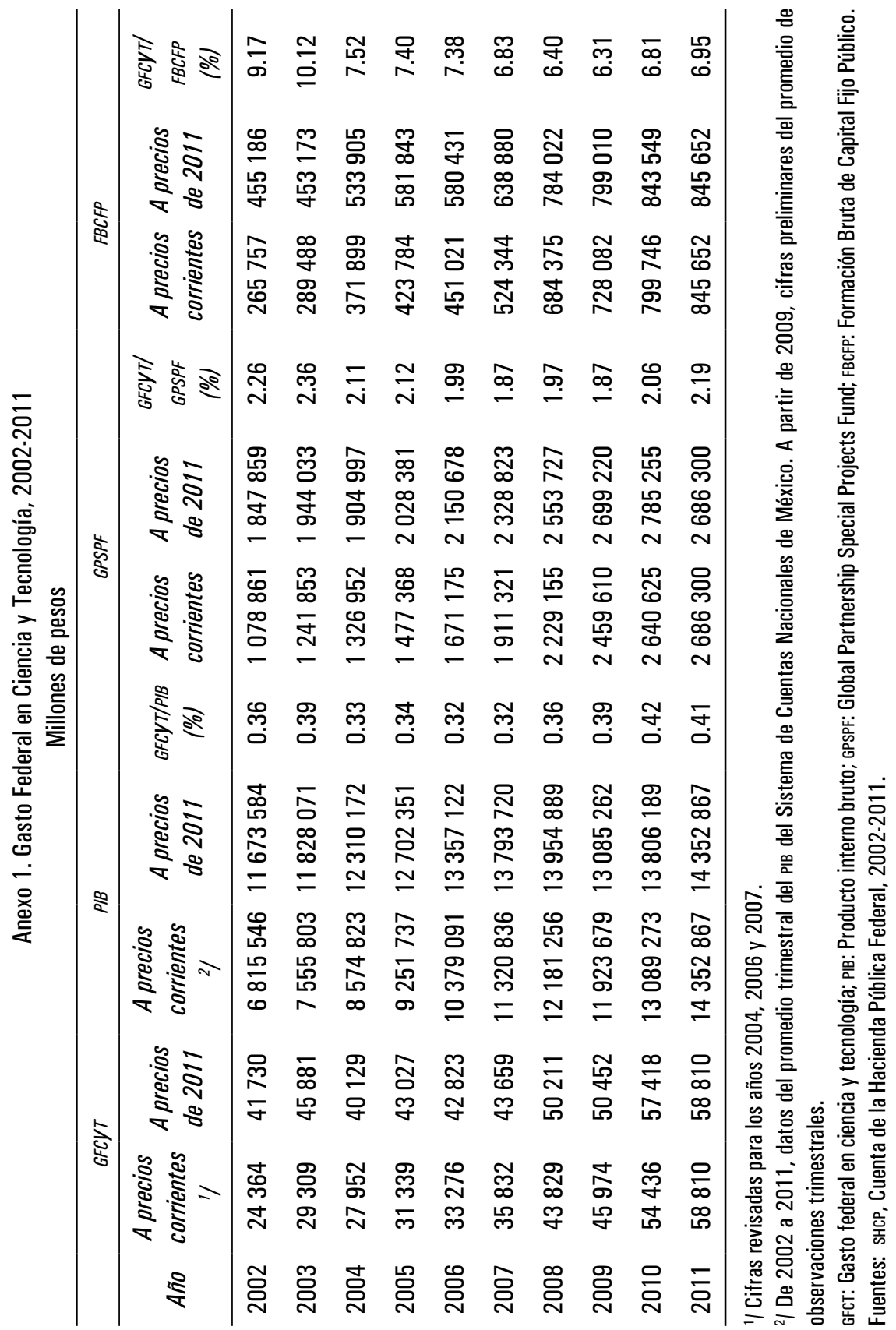




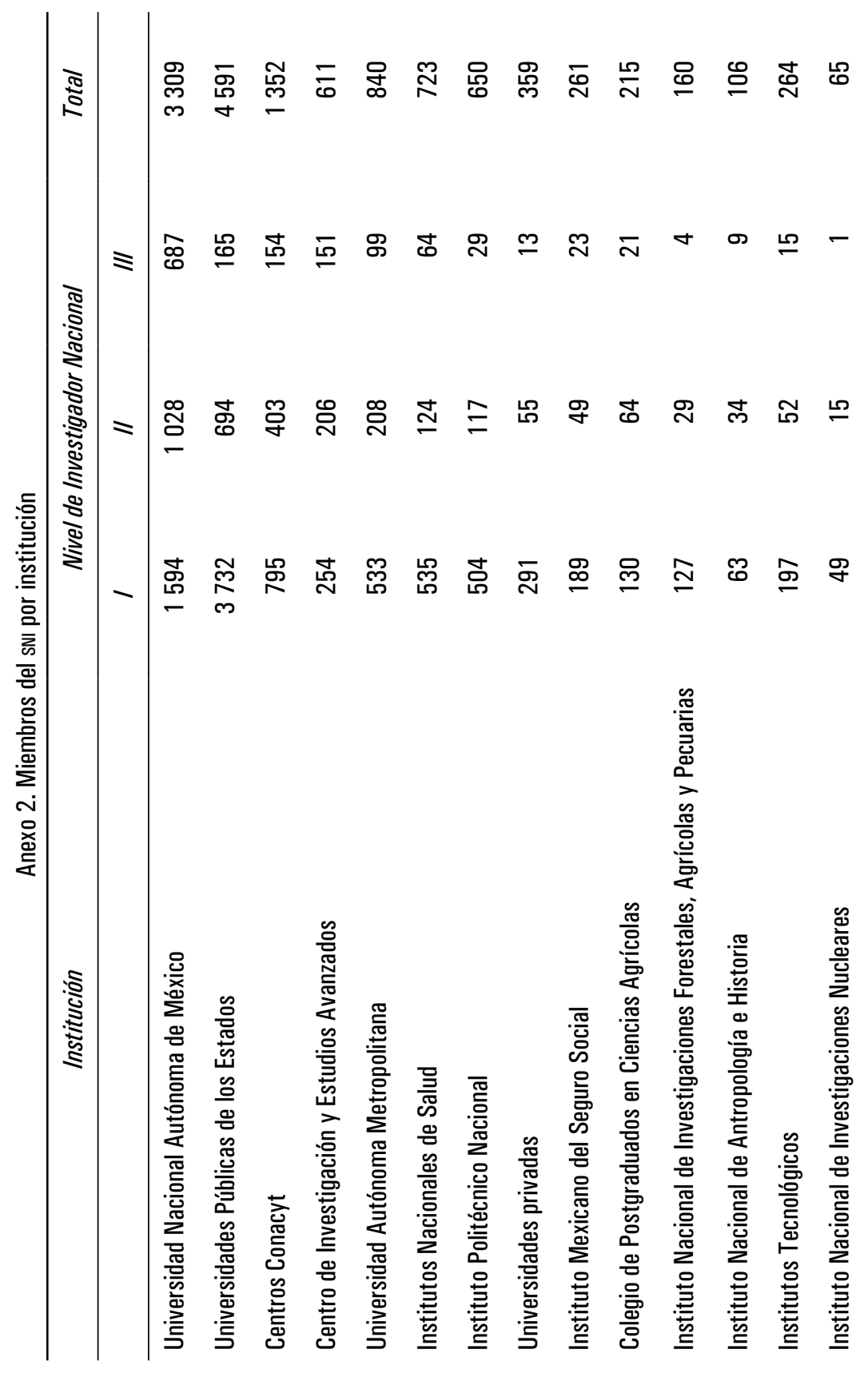




$$
\begin{aligned}
& \text { 도ำ } \\
& \text { - } 0 \text { เ } \\
& \text { ம }
\end{aligned}
$$

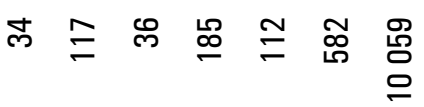

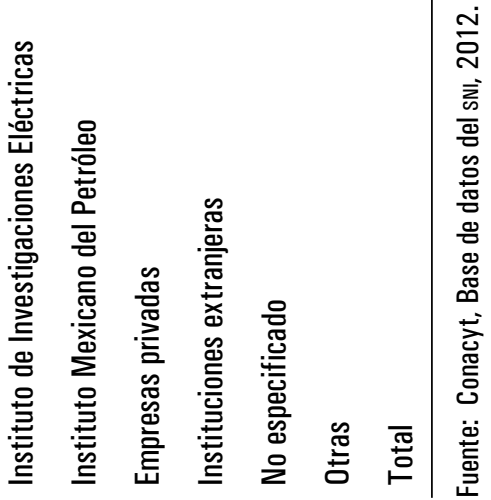


Anexo 3. Artículos publicados por científicos mexicanos por disciplina

\begin{tabular}{|c|c|c|c|c|}
\hline Disciplina & 2003 & 2006 & 2009 & $2011^{*}$ \\
\hline Agricultura & 282 & 329 & 385 & 425 \\
\hline Astrofísica & 206 & 213 & 288 & 278 \\
\hline Biol. molecular & 108 & 121 & 159 & 172 \\
\hline Biología & 337 & 366 & 466 & 491 \\
\hline Ciencias sociales & 155 & 187 & 420 & 451 \\
\hline Computación & 122 & 197 & 107 & 108 \\
\hline Ecología & 282 & 413 & 354 & 465 \\
\hline Economía & 42 & 59 & 82 & 102 \\
\hline Farmacología & 104 & 127 & 168 & 180 \\
\hline Física & 946 & 919 & 1054 & 1128 \\
\hline Geociencias & 234 & 270 & 371 & 389 \\
\hline Ingeniería & 476 & 551 & 726 & 762 \\
\hline Inmunología & 62 & 89 & 116 & 132 \\
\hline Matemáticas & 180 & 217 & 273 & 302 \\
\hline Materiales & 278 & 418 & 492 & 490 \\
\hline Medicina & 641 & 774 & 1057 & 1261 \\
\hline Microbiología & 156 & 159 & 217 & 218 \\
\hline Multidisciplinarias & 2 & 2 & 18 & 17 \\
\hline Neurociencias & 179 & 181 & 229 & 254 \\
\hline Plantas y animales & 755 & 868 & 1470 & 1640 \\
\hline Psicol. y psiq. & 108 & 125 & 125 & 144 \\
\hline Química & 579 & 649 & 911 & 1043 \\
\hline Total & 6234 & 7234 & 9488 & 10449 \\
\hline
\end{tabular}

* Cifras estimadas.

Fuente: Institute for Scientific Information, 2010. 
Anexo 4. Patentes de mexicanos en el extranjero

\begin{tabular}{|c|c|c|c|c|}
\hline País & 2000 & 2003 & 2006 & 2009 \\
\hline Alemania & 5 & 2 & 0 & 4 \\
\hline Australia & 7 & 5 & 13 & 11 \\
\hline Brasil & 20 & 25 & 31 & 35 \\
\hline Canadá & 8 & 6 & 31 & 39 \\
\hline Chile & 15 & 10 & 6 & 10 \\
\hline China & 9 & 5 & 20 & 18 \\
\hline Colombia & 9 & 0 & 0 & 0 \\
\hline Corea del Sur & 7 & 5 & 11 & 12 \\
\hline España & 7 & 8 & 4 & 1 \\
\hline Estados Unidos & 190 & 185 & 213 & 220 \\
\hline Francia & 1 & 0 & 2 & 0 \\
\hline Holanda & 0 & 0 & 1 & 1 \\
\hline Hong Kong & 1 & 5 & 5 & 2 \\
\hline India & 3 & 1 & 16 & 8 \\
\hline Israel & 1 & 3 & 2 & 4 \\
\hline Italia & 0 & 0 & 0 & 0 \\
\hline Japón & 2 & 2 & 24 & 21 \\
\hline Nueva Zelanda & 0 & 0 & 1 & 2 \\
\hline Reino Unido & 2 & 0 & 0 & 2 \\
\hline Rusia & 5 & 1 & 8 & 11 \\
\hline Singapur & 0 & 2 & 6 & 2 \\
\hline Suecia & 0 & 0 & 1 & 0 \\
\hline Suiza & 3 & 0 & 0 & 0 \\
\hline $\begin{array}{l}\text { European Patent } \\
\text { Office (EPO) }\end{array}$ & 5 & 3 & 47 & 51 \\
\hline Otros países & 463 & 475 & 588 & 870 \\
\hline Total & 763 & 743 & 1030 & 1324 \\
\hline
\end{tabular}

Fuente: Informe anual, Conacyt, 2012. 
Mitos y realidades de la ciencia en México es una obra del Instituto de Investigaciones Económicas de la Universidad Nacional Autónoma de México. Se terminó de imprimir el 17 de octubre de 2014 en los talleres de Fuentes Impresores, S.A. de C.V., Centeno 19, col. Granjas Esmeralda, CP 09810, México, D.F. El tiraje consta de 500 ejemplares en impresión offset, en papel cultural de 80 gr. y los forros en couché de 240 gr. La formación estuvo a cargo de José Dolores López Sánchez; se utilizaron fuentes Century Schoolbook de 9, 10 y 11 puntos y Univers Condensado 9 y 10 puntos. El cuidado de la edición estuvo a cargo de Hélida De Sales Y. 